\title{
Static, Free Vibration and Buckling Analysis of Composite Panels; A Review
}

\author{
Sreadha A R ${ }^{1 *}$, C. Pany ${ }^{2}$ \\ ${ }^{1}$ Department of Civil Engineering, Amal Jyothi College of Engineering, Kanjirapally, India \\ ${ }^{2}$ VSSC, Trivandrum, Kerala, India
}

* Corresponding Author email: a.r.sreadha@gmail.com

Article History

Received: 13 July 2020

Revised: 10 October 2020

Accepted: 29-October 2020

Published: 27 November 2020

Student(s)

- Sreadha A R

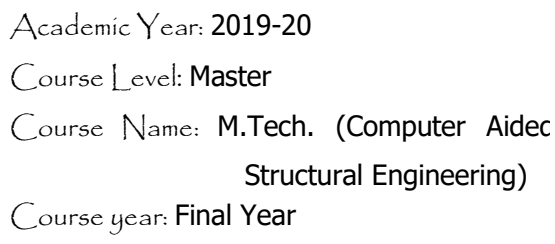

Mentar(s)

- Chitaranjan Pany

\begin{abstract}
A composite material is generally a combination of materials differing in composition or form on a macro scale for the purposes of attaining specific characteristics and properties. The developments in the field of composite materials have granted significant weight reduction in structural design. When compared to metallic materials, composites offer many advantages, especially high strength, stiffness to weight ratio, excellent fatigue properties, and corrosion resistance. Plates, curved panels, the cylindrical shell-shaped forms of models are being broadly used in many structural packages of engineering structure. For design the structure, it is important to know the behaviour of these under static, free vibration, buckling condition. The present paper aims to review the literature on static, free vibration, and buckling analysis of composite flat panel, curved panel, and cylindrical shell. Further, the testing procedure of laminate, design guidelines of laminates and cost estimations with mechanical properties comparison of laminate with metal, CLT (classical lamination theory) basis including thermal and moisture expansion for stiffness evaluation are also summarised in this paper.
\end{abstract}

Keywords: Composite, Structural, Aerospace, Static, Free vibration, Buckling

\section{Introduction}

The composite materials are composed of matrix and reinforcement, and when combined gives properties better than individual components. The reinforcement is often supplied in the form of fibres and the matrix materials are often made of metals, ceramics, or polymers. The fibres are impregnated with a matrix material which transfer loads to the fibers, provide toughness, protect the fibres from adverse environmental attack, abrasion and keeps the fibre in the desired orientation. Fibres give strength and stiffness and carry the applied structural load. Composite laminates are formed with the aid of stacking layers of various composite substances and/or fiber orientation. Developments in the field of composite materials have resulted in a significant reduction in structural design weight. Composite materials have been used extensively in various 
fields of engineering in particular such as wing structures and fuselage panels of aircraft, commercial airliners or fighter jets, automotive body parts, launch vehicle upper stage cryogenic hydrogen fuel tanks, spacecraft, marine, sports, biomedical, heavy machinery, agricultural equipment and health devices, industrial machinery, carbon nanotube etc[1-6].

As compared to metallic alloys, composite materials offer many advantages, particularly when it comes to high strength and stiffness to weight ratios, much higher resistance-to-weight ratio than metal [1]. Composites offer a number of features such as lightweight due to high specific strength and stiffness, fatigue resistance and corrosion resistance[4], high modulus, low specific density, long fatigue life, resistance to electrochemical corrosion, good electrical and thermal conductivity, high optimization capability, alignment of directional strength and stiffness, good for thin-walled or generously curved construction, ability to preserve dimensional and orientation stability in the space environment, ability to achieve low cross-section. By construction requirements, composite laminates have their planar dimension one to two orders of magnitude larger than their thickness. Hence, the composite laminates are treated as plate components. The CFRP (carbon fibre reinforced plastic), GFRP (glass fibre reinforced plastic) composite type is used by a wide variety of industries [1-3].

In this paper the literature review is focused on the scope of static, bucking \& free vibration analysis of composite flat panels, curved panels and shells. Further design guidelines and testing procedure for mechanical properties evaluation of composite laminate are summarized. The conclusions are made based on the above study, will be useful for designer, researcher in design of laminated composite structure.

\section{Laminated Composites}

Laminar composites are found in as many combinations as the number of materials. They may be defined as materials comprising layers of materials bonded together. These may consist of multiple layers of two or more metal materials that appear alternately or more than once in a specified order, and in as many numbers as is necessary for a particular reason. The matrix is to assist and protect the fibres and to distribute load amongst and transmitting load between, the fibres. The latter function is especially critical if fibre breaks [1].

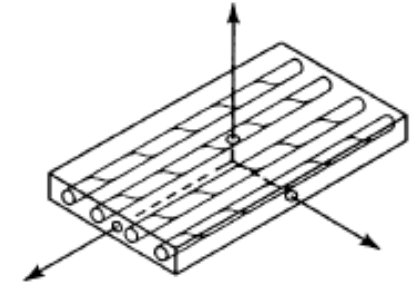

LAMINA WITH UNIDIRECTIONAL FIBERS

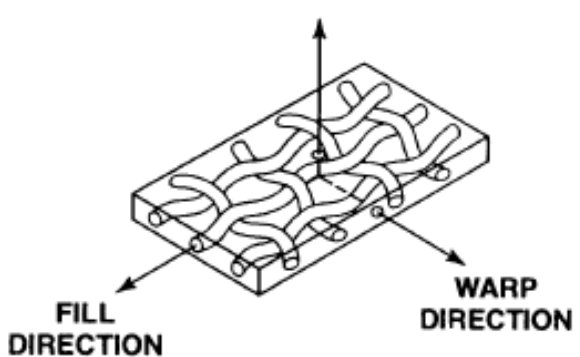

LAMINA WITH WOVEN FIBERS

Figure 1: Two principal types of laminae [1]

A laminate is a bonded stack of laminae with the various orientation of principal material in the laminae shown in Fig 1. A laminate is created by combining multiple layers of various materials or by adding different layers of reinforcement in a matrix.

The definition on the laminate provides the following details: (i) Orientation of each lamina with respect to the $\mathrm{x}$-axis(ii) The number of laminates for different orientation (iii) Exact geometrical form on laminate. In the counter-clockwise direction, the orientation angle $\theta$ is positive. The number of layers in the ply group is specified in a numeric subscription. For example, the laminate designated as $\left[90^{\circ}, 45^{\circ}, 0^{\circ}\right] \mathrm{s}$. This laminate contains totally 10 layers, one $90^{\circ}$ layer on the top and bottom, three $45^{\circ}$ layers next to $90^{\circ}$ layer on both sides and two $0^{\circ}$ layers in the middle. The subscript 's' denotes that the laminate is symmetric $[1,2]$. 


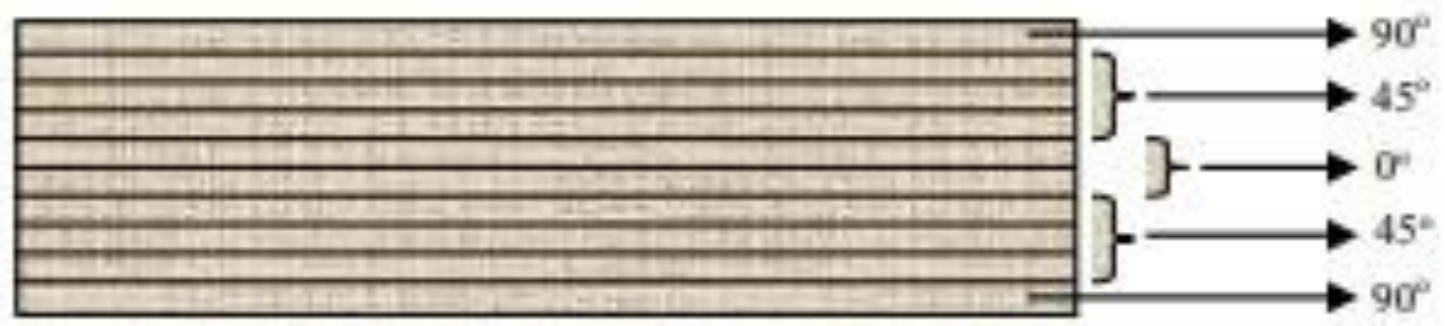

Figure 2: Orientation of $\left[90^{\circ} / 45^{\circ}{ }_{3} / 0^{\circ}\right]_{s}$ laminate [1]

Symmetric laminate: In a symmetrical laminate, the ply direction around the midplane of the laminate is symmetrical; that is, with each ply above the midplane, there is a similar ply at an equal distance below the midplane. Thus, for a symmetric laminate, $\theta(z)=\theta(-z)$ where $z$ is the distance from the mid-plane of the laminate.

Anti-symmetric laminate: For every ply above the midplane with orientation angle ' $\theta$ ', there's every other ply under the midplane with orientation angle ' $-\theta$ '. Both plies will possess the same mechanical and physical properties. Thus, for an anti-symmetric laminate, $\theta(z)=-\theta(-z)$. For example, $[\theta /-\theta / \theta /-\theta]$ is an antisymmetric laminate. In the anti-symmetric laminate, there is always an even number of layers.

Un-symmetric laminate: A laminate is considered un-symmetric, when it is neither symmetric nor antisymmetric. For example, $\left[0^{\circ} / 45^{\circ} / 90^{\circ}\right],\left[0^{\circ} / 0^{\circ} / 0^{\circ} / 90^{\circ}\right],[+\theta /-\theta /-\theta],[-\theta /+\theta /+\theta]$ etc are un-symmetric laminates.

Quasi-isotropic laminate: These laminates are composed of three or more identical thickness and material laminates with the same angle between each adjacent laminate. Thus, if the total number of laminae is $\mathrm{N}$, the orientation angles of the laminate are at an increment of $\pi / \mathrm{N}$. The laminate properties are isotropic in the 1-2 (x-y) plane. For example, [0/ \pm 60$],[0 / \pm 45 / 90] s$, and $[0 / 36 / 72 /-36 /-72]$ etc:- are quasi-isotropic laminate.

Unidirectional laminate: Each laminate has the same angle of fibre orientation. For example, in unidirectional $0^{\circ}$ laminates, $\theta=0^{\circ}$ in all laminate.

Angle-ply laminate: A laminate is referred to angle-ply laminate if it has piles of same thickness and material and is oriented towards at $+\theta$ and $-\theta$. $[45,-45,30,-30]$ is an example for angle ply laminate.

Cross-ply laminate: In cross-ply laminate, only $0^{0}$ and $90^{\circ}$ are used in all plies to produce the laminate. [ $0^{\circ}$ $190^{\circ} / 0^{\circ} / 90^{\circ}$ is an example for cross-ply laminate. In a cross-ply laminate there could be no extension shear coupling.

Balanced laminate: For every lamina, with orientation angle ' $\theta$ ', there exists another lamina with orientation ' $\theta$ ' anywhere in the thickness direction. In a balanced laminate, there would be no extensionshear coupling. [30。 $\left./-30^{\circ} / 60^{\circ} /-60^{\circ}\right]$ is an example for balanced laminate.

Antisymmetric cross-ply laminate: Anti-symmetric laminate consists of plies orientated to $0^{\circ}$ and $90^{\circ}$ orientated plies so that there is another $90^{\circ}$ ply at the same distance from the middle plane for each $0^{\circ}$ ply. Such laminates should have extensions/bends of coupling. $\left[0^{\circ} / 90^{\circ} / 0^{\circ} / 90^{\circ}\right]$ is an example for antisymmetric cross-ply laminate.

\subsection{Classical laminate theory (CLT)}

CLT describes the relationship between the loadings (in-plane forces, out-of-plane bending moments and, extension, temperature, moisture) and the deformations (in-plane strain and out-of-plane curvatures) of the laminate. The strains and curvatures of the midplane induced into the laminate. The matrix showing deflections of the laminate is shown below 


$$
\left[\begin{array}{c}
\varepsilon_{x x}^{0} \\
\varepsilon_{y y}^{0} \\
\varepsilon_{x y}^{0} \\
K_{X X} \\
K_{Y Y} \\
K_{X Y}
\end{array}\right]=\left[\begin{array}{llllll}
a_{11} & a_{12} & a_{16} & b_{11} & b_{12} & b_{16} \\
a_{12} & a_{22} & a_{26} & b_{12} & b_{22} & b_{16} \\
a_{16} & a_{26} & a_{66} & b_{16} & b_{26} & b_{66} \\
b_{11} & b_{12} & b_{16} & d_{11} & d_{12} & d_{16} \\
b_{12} & b_{22} & b_{26} & d_{12} & d_{22} & d_{26} \\
b_{16} & b_{26} & b_{66} & d_{16} & d_{26} & d_{66}
\end{array}\right] \cdot\left[\begin{array}{c}
N_{x x}+N_{x x}^{T}+N_{x x}^{M} \\
N_{y y}+N_{y y}^{T}+N_{y y}^{M} \\
N_{x y}+N_{x y}^{T}+N_{x y}^{M} \\
M_{x x}+M_{x x}^{T}+M_{x x}^{M} \\
M_{y y}+M_{y y}^{T}+M_{y y}^{M} \\
M_{x y}+M_{x y}^{T}+M_{x y}^{M}
\end{array}\right]-
$$

Force resultant $N_{x x}, N_{y y}, N_{x y}$; Thermal Resultants: $N_{X X}^{T}, N_{Y Y}^{T}, N_{X Y}^{T}, M_{X X}^{T}, M_{Y Y}^{T}, M_{X Y}^{T}$; Moisture Resultants: $N_{X X}^{M}, N_{Y Y}^{M}, N_{X Y}^{M}, M_{X X}^{M}, M_{Y Y}^{M}, M_{X Y}^{M}$

Usually, the relation is called the ABD matrix, in which a describes the laminate 's membrane stiffness, $\mathrm{b}$ the coupling stiffness, and $\mathrm{d}$ the bending stiffness.

$$
\left[\frac{\varepsilon^{0}}{\mathrm{k}}\right]=\left[\begin{array}{ll}
\mathrm{a} & \mathrm{b} \\
\mathrm{b} & \mathrm{d}
\end{array}\right]\left[\frac{\mathrm{N}}{\mathrm{M}}\right]
$$

The ABD matrix in brackets is the laminate compliance matrix, and its inverse will be the laminate stiffness matrix. Cross-sectional forces and moments can be recognized by means of summing the combined stress components on each ply. Several types of mechanical coupling in a general laminate are shown in eq. 1. These are grouped together as follows:

$\begin{array}{ll}\text { Extension-Shear: } \mathrm{a}_{16}, \mathrm{a}_{26} & \text { Extension-Bending }: \mathrm{b}_{11}, \mathrm{~b}_{12}, \mathrm{~b}_{22} \\ \text { Extension-Twisting: } \mathrm{b}_{16}, \mathrm{~b}_{26} & \text { Shear-Bending: } \mathrm{b}_{16}, \mathrm{~b}_{26} \\ \text { Shear-Twisting: } \mathrm{b}_{66} & \text { Bending-Twisting: } \mathrm{d}_{16}, \mathrm{~d}_{26} \\ \text { Biaxial-Extension: } \mathrm{a}_{12} & \text { Biaxial-Bending: } \mathrm{d}_{12}\end{array}$

The stress on each ply can be calculated in global co-ordinate as follows

$\left[\begin{array}{l}\sigma_{x x} \\ \sigma_{y y} \\ \tau_{x y}\end{array}\right]=\left[\begin{array}{lll}\overline{Q_{11}} & \overline{Q_{12}} & \overline{Q_{16}} \\ \overline{Q_{12}} & \overline{Q_{22}} & \overline{Q_{26}} \\ \overline{Q_{16}} & \overline{Q_{26}} & \overline{Q_{66}}\end{array}\right] \cdot\left\{\begin{array}{l}\varepsilon_{x x-\Delta T} \alpha_{x x}-\Delta M \beta_{x x} \\ \varepsilon_{y y-\Delta T} \alpha_{y y}-\Delta M \beta_{y y} \\ \varepsilon_{x y-\Delta T \alpha_{x y}-\Delta M \beta_{x y}}\end{array}\right\}$

Where the mechanical strain in the $\mathrm{x}$-y coordinate system for ply strains as follows

$$
\left\{\begin{array}{l}
\varepsilon_{x x} \\
\varepsilon_{y y} \\
\gamma_{x y}
\end{array}\right\}=\left\{\begin{array}{l}
\varepsilon_{x x}^{0} \\
\varepsilon_{y y}^{0} \\
\gamma_{x y}^{0}
\end{array}\right\}+z\left\{\begin{array}{l}
K_{x x} \\
K_{y y} \\
K_{x y}
\end{array}\right\}
$$

In equation (3), Qij are corresponds to reduced stiffness matrix terms, $\left(\Delta \mathrm{T} \alpha_{\mathrm{xx}}, \Delta \mathrm{T} \alpha_{\mathrm{yy}}, \Delta \mathrm{T} \alpha_{\mathrm{xy}}\right),\left(\Delta \mathrm{M} \beta_{\mathrm{xx}}, \Delta \mathrm{M} \beta_{\mathrm{yy}}, \Delta \mathrm{M} \beta_{\mathrm{xy}}\right)$ are strains due to temperature and moisture respectively. In equation (4), $\varepsilon_{\mathrm{xx}}^{0}, \varepsilon_{\mathrm{yy}}^{0}$ and $\gamma_{\mathrm{xy}}^{0}$ are mid plane mechanical strains and $\mathrm{K}_{\mathrm{xx}}, \mathrm{K}_{\mathrm{yy}}, \mathrm{K}_{\mathrm{xy}}$ are curvatures terms.

\section{Study of test methods}

The details of the materials and its fundamental constituents, the fabrication of composite laminate, and the test methods according to standards are described.

\subsection{Fabrication method}

Here only hand layup technique is described. Specimens were cast using hand layup technique, the percentage of fibre and matrix was taken as $60: 40$ by weight for the fabrication of the laminate. In the lamination process initially, gel coat (epoxy and hardener) applied on the mould by brush. Reinforcement layers were placed on the mould at top of the gel coat and again repeat the procedure with gel coat application with the brush. Steel rollers are used to remove any air which may be entrapped. At the end of completion layup of all layers, a plastic sheet is covered at the top of the last ply with applying polyvinyl alcohol at the bottom of the sheet as releasing agent. Subsequently, one flat plyboard and a heavy flat metal rigid platform are kept over the top of the plate as a deadweight for compression. The plates were left for 
a minimum of 48 hours in room temperature before further processing i.e. coupon making (cutting to required shape for testing).

The physical properties of manufactured composite plates including density and thickness, were measured up to the required degree of accuracy. The thickness was measured using a $0.1 \mathrm{~mm}$ vernier caliper. The weight of the specimen was measured using digital weighing balance with an accuracy of 0.1 grams.

\subsection{Tensile strength}

The Young's modulus was obtained experimentally by performing unidirectional tensile tests on specimens cut in longitudinal and transverse directions as described in ASTM Standard [3] for the FRP plates fabricated earlier. Strips of specimens having a constant rectangular cross-section, say $250 \mathrm{~mm}$ long $\times$ $25 \mathrm{~mm}$ width are prepared from the plates. Three or more CFRP sample specimens are prepared for the experiment. The specimen is gradually loaded up to failure, which is happened abrupt and sudden as the FRP material was brittle in nature. The INSTRON 1195 machine is used to find the Young's Modulus, ultimate strength. The load was displayed in $\mathrm{kN}$ units, divided into the original cross-sectional area at the moment of rupture and the strength of the tensile was measured. The tensile modulus is measured using a set of extensometers.

\subsection{Compressive strength}

The test method is used for compression of laminates which contain fibers in multiple fiber directions, especially axial $\left(0^{0}\right)$ fibers and off-axis $\left( \pm \theta^{\circ}\right)$ fibers combined. SACMA SRM-1 (also known as D695 modified), D3410 / D3410 M, D5467 / D5467 M, D6641 / D6641 M and D7249 / D7249 M are also used in other compression strength test methods. SRM-1 research utilizes 12.6-mm wide specimens, which are only appropriate for the single-way film, cross-ply [0/90] ns or 3K-70-P thin single-cell fabrics, plainwoven dry graphite. Larger cell fabrics will be checked with $12 \mathrm{~K}$ spread-tow fabrics, a synthetic fiber cloth with broader specimens. Standard D3410 / D3410 M and D6641 / D6641 M test fittings allow for the use of larger specimens, for example, $25.4 \mathrm{~mm}$ wide. Thus, laminates which contain axial and off-axial fibre may be tested. The D5467 / D5467 M test method is intended as a unidirectional laminate for compressive strength, but due to the configuration of the sandwich beam, is expensive. The D7249 / D7249 M Test method is designed to achieve the sandwich facial sheet strength. The test will give un-notched compressive strength, ultimate compressive strain, compressive modulus of elasticity and Poisson's ratio in compression. Compression strengths include the following factors: materials, materials manufacturing methods, layout accuracy, laminate stacking sequence and general thickness, specimen preparation, sample conditioning, testing environment, alignment and gripping of specimens, testing speed, temperature time and void and volume reinforcement percentage [7].

\subsection{Shear strength}

A tension test on [+/-45] s laminate is popularly used test for the measurement of in-plane shear Modulus $\mathrm{G}_{12}$. The more details of this test are available in ATSM standard D3518/D3518 /M91. According to ASTM standard the method uses a $250 \mathrm{~mm}$ long rectangular specimen with width $25 \mathrm{~mm}$ and thickness $2 \mathrm{~mm}$. Further, it is recommended that for materials having thickness more than $0.125 \mathrm{~mm}$, the laminate should have 16 layers, that is, $[+/-45]_{4 \mathrm{~s}}$.

\subsection{Inter laminar shear strength (ILSS)}

The ILSS is the ability to resist delamination damage of parallel fibre composites. The short beam shear (SBS) test (three point-bending) subjects a bending beam, the beam being very short relative to its thickness. ASTM D 2344 defines the support span to the specimen thickness ratio of 6:1 only. The objective is to minimize the flexural (tensile and compressive) stresses and to maximize the induced shear stress. The load increases with deformation in proportion to SBS bending until a peak load is reached. If the load decreases 
by $30 \%$ or more immediately after the maximum load is reached, the specimen is expected to fail in lamina shear and to assess the apparent ILSS by using peak load.

In accordance with the following reference, the ILSS values were determined by a short beam shear test:

$$
\text { ILSS }=0.75 \mathrm{~Pb} / \mathrm{bd}
$$

Where $\mathrm{Pb}=$ breaking load, $\mathrm{b}=$ width and $\mathrm{d}=$ specimen thickness.

The ILSS value in glass fibre composite is almost the same value as that of carbon fibre reinforced epoxy matrix composite. This result indicates that the ILSS value predominantly depends on the matrix material and minimal contribution of fibres in the two-phase composite materials. However, for the Hybrid material (three-phase), the ILSS value is significantly improved by $35 \%$, this is due to the contribution of carbon and glass fibres along with matrix material [8]. A minimum of five specimens is required in each sample, as per ASTM D2344.

Aslan and Alnak [9] carried out ILSS test and results obtained from four-point bend shear tests were compared with that obtained from ASTM test standards D2344 (SBS). The research findings show that the effects of the four-point bend interlaminar shear test at a span-to-thickness ratio of 8 are better than the results of the short beam shear test.

\section{Equation of motion for Static, buckling and Free vibration}

The equation of motion for static, buckling and free vibration of a laminated composite panel, may be expressed in the matrix form as:

\subsection{Static}

$[\mathrm{K}]\{\mathrm{d}\}=\{\mathrm{F}\}$

Where, $[\mathrm{K}]=$ Stiffness matrix; $\{\mathrm{d}\}=$ displacement vector; $\{\mathrm{F}\}=$ Force vector

\subsection{Buckling}

$([\mathrm{K}]+\lambda[\mathrm{S}])\{\mathrm{d}\}=\{0\}$

Where $[\mathrm{K}]=$ stiffness matrix $[\mathrm{S}]=$ stress stiffness matrix $\lambda=$ Buckling factor

\subsection{Free Vibration}

$\left([\mathrm{K}]-\Omega^{2}[\mathrm{M}]\right)\{\Psi\}=0$

Where $[\mathrm{K}]=$ stiffness matrix $[\mathrm{M}]=$ mass matrix $\Omega=$ Eigen values $\Psi=$ Eigen vector

\section{Laminate Design Guidelines}

Haftka R.T et al.[10] to find the efficient composite structural design which fulfills the requirements of a particular application, the selective use of the orientation, number and stacking sequence of laminae that make up the composite laminate can be achieved not only by the division of cross areas and member thicknesses but also by the global or local tailoring of the material proprieties.

F.-X. Irisarria et al. [11] implement the concept of the stacking sequence table (SST) to ensure the optimal design of laminated composite structures with ply drops. The SST describes the ply drop sequence which ensures that a thicker and thinner laminated guidance is transited. An SST is a blended design, combined with a spread of spacing across structural areas. A SST in combination with a thickness distribution across structural regions is a blended design.

The laminate design guidelines are considered as a basis for the design of the stacking sequences of most composite structures in the aerospace industry. A more detailed discussion about design guidelines and their justifications is provided in [11-15]. Based on a particular application, the laminate design is carried out by selecting the set of ply angles. Due to manufacturing constraints, the allowed ply orientations are reduced to a discrete set of angles such as $\left\{0^{\circ}, \pm 15^{\circ}, \pm 30^{\circ}, \pm 45^{\circ}, \pm 60^{\circ}, \pm 75^{\circ}, 90^{\circ}\right\}$. Once the angles are selected, the total number of plies and the proportion of each orientation in the laminate is set and a stacking sequence is chosen. Further, during designing structures that consists of several zones of variable 
thicknesses, thickness variations are assigned by dropping off plies at specific locations. Many guidelines are applied in both laminate sequence design and ply-drop-off design, which are based on industry experience in testing and analysis.

1. Stacking sequences whenever possible should be symmetrical about the mid-plane. To avoid warping from the coupling between in-plane strains and out-of-plane rotations (curvature $\&$ twists), unless warping is desired. $[B]=0$ for symmetric laminates.

2. Stacking sequences should be balanced, with the same number of $+\theta^{\circ}$ and $-\theta^{\circ}$ plies $(\theta \neq 0$ and $\theta \neq 90)$. Which reduces in-plane coupling of normal strains and in-plane shear strains $\left(A_{16}=A_{26}=0\right.$ for balanced laminates) and to minimize the coupling of curvatures and torsions $\left(\mathrm{D}_{16}=\mathrm{D}_{26}=0\right.$ for symmetric and balanced laminates). The guidelines on symmetry and balance aim at avoiding coupling of the shear extension and membrane bending respectively.

3. Not more than 4 piles should be stacks in any one direction together to ensure that the similarly oriented ply stack is not contiguous with the adjacent flies.

4. The difference between the orientations of two consecutive plies should not exceed $45^{\circ}$ for disorientation.

5. A minimum of $10 \%$ of plies in each of the $0^{\circ}, \pm 45^{\circ}$ and $90^{\circ}$ directions are required. This rule is transposed in all directions in order to accommodate the other ply orientations in terms of minimum stiffness requirements [16]. 10 per cent rule is advantageous to prevent matrix regulated behaviours and modes of failure such as free-random delamination (disorientation) or spread of cross matrix cracking (contiguity).

6.: The lower and upper surfaces of the laminate should not be put $0^{\circ}$ ply to avoid damage tolerance.

7. The $0^{\circ}$ plies orientation to take axial loads, $45^{\circ}$ to carry Shear loads and transverse loads with $90^{\circ}$ plies. So, the panel would be stable relative to any stress if we build it using a $60^{\circ} / 30^{\circ} / 10^{\circ}$ configuration.

8. Laminates carrying predominantly shear loads but some normal loads (stringer stiffened skin panels) should be a ply combination of $10 \% 00^{\circ}, 80 \% 45^{\circ}, 10 \% 90^{\circ}$.

9. Laminates carrying axial loads (certain stiffeners, beam chords etc) should be combination of $60 \%$ $0^{\circ}, 30 \% 45^{\circ}, 10 \% 90^{\circ}$, or even a higher percentage of $0^{\circ}$.

10. Laminates should have a minimum of $8 \%$ fibres in each major direction $\left(0^{\circ}, 45^{\circ}, 90^{\circ}\right)$ to account for unexpected loads.

11. The $0^{\circ} \& 90^{\circ}$ plies should be separated by + or $-45^{\circ}$ ply, or preferably by $+45^{\circ}$ and $-45^{\circ}$ ply, to avoid delamination between the $0^{\circ}$ ply and that $90^{\circ}$ ply due to Poisson's misalignment.

12. Avoid placing a stack of similarly oriented plates on the laminate's outer surface because they are more prone to damage for example, $0^{0}, 90^{\circ}$ (or fabric) is more damage tolerant than $0^{\circ}$.

13. $45^{0}, 90^{\circ},-45^{0}$ sequences are often used at outer surfaces since these sequences are more damage resistant and more damage tolerant than stacks of similarly oriented plies. This also contains the load-carrying similarly oriented stacks within the laminate and helps prevent delamination under load.

14. Use fabric in outer ply in place of tape to give abrasion resistance. The fabric also reduces fibre breakdown when hole boilers are drilled.

15. The load-carrying plies should be placed for safety against the centre. For example, the $0^{\circ}$ plies should not place on the outside of the beam to minimize damage.

16. To prevent delamination, avoid free edges. Repeated loading causes delamination at ends with the maximum interlaminar (out-of-plane) stress at the open edges.

If we follow above rules, the strength of the structure will improve. The ply-drop design guidelines aim first at avoiding delamination at a ply-drop location and, secondly, at obtaining ply layouts that can be manufactured with current techniques as follows.

17. The covering plies on the lower and upper surfaces of the laminate should not be dropped off. 
18.: Te maximum taper slope should not exceed a maximum inclination. Here, the maximum inclination should be minimal stagger distance (the length of the increment of thickness) is about eight times the thickness of the dropped plies.

19. The maximum number of plies may be stopped at the same increment of thickness. .

20. Continuous binding between consecutive ply drops should be maintained (internal continuity). Three dropped plies for a continual ply are permitted.

21. Alternatively ply-drops can be located near to and far from the middle portion of the laminate.

22. All laminates in the taper section should respect the laminate design guidelines to the maximum possible extend.

23. However, the global requirements must also be met when designing a variable-thickness composite structure. (a) Continuity: the requirement aims at ensuring structural integrity and manufacturability of the structure. The thinner-panel plies shall cover the entire structure. Ply orientation mismatches between adjacent panels are not allowed. (b) Constraining the thickness variation between adjacent zones may contribute to smoothing the load distribution over the structure (i.e. avoid high-stress concentrations especially interlaminar stresses) at dropped plies.

\section{Cost comparison and mechanical properties}

Performance Composites Inc. [17] has shown a comparison of costs and mechanical properties of graphite composite, fiber glass composite, aluminum, and steel has been presented in Table-1. Because of the wide variety of available graphite fibers and resins and the many material combinations, the properties are tabulated in form of ranges.

Table 1: Costs and mechanical properties of graphite composite, fiberglass composite, aluminum and steel

\begin{tabular}{|c|c|c|c|c|c|}
\hline & $\begin{array}{c}\text { Graphite } \\
\text { Composite } \\
\text { (aerospace grade) }\end{array}$ & $\begin{array}{c}\text { Graphite } \\
\text { Composite } \\
\text { (commercial } \\
\text { grade) }\end{array}$ & Fibreglass Composite & $\begin{array}{l}\text { Aluminium } \\
6061 \mathrm{~T}-6\end{array}$ & Mild Steel \\
\hline Cost in ₹/Kg & ₹ 3316 - ₹ 41447 & ₹ 829 -₹3316 & ₹248.7 - ₹497.4 & ₹498 & ₹50 \\
\hline $\begin{array}{l}\text { Strength } \\
\text { (kpa) }\end{array}$ & $\begin{array}{l}620.52 \times 10^{3}- \\
1378.95 \times 10^{3}\end{array}$ & $\begin{array}{l}344.73 \times 10^{3}- \\
620.52 \times 10^{3}\end{array}$ & $\begin{array}{l}137.89 \times 10^{3}- \\
241.31 \times 10^{3}\end{array}$ & $241.31 \times 10^{3}$ & $413.68 \times 10^{3}$ \\
\hline $\mathrm{E}(\mathrm{kpa})$ & $\begin{array}{l}68.94 \times 10^{6}- \\
344.73 \times 10^{6}\end{array}$ & $\begin{array}{c}55 . .15 \times 10^{6}- \\
68.94 \times 10^{6}\end{array}$ & $6.89 \times 10^{6}-10.34 \times 10^{6}$ & $68.94 \times 10^{6}$ & $206.84 \times 10^{6}$ \\
\hline $\begin{array}{l}\text { Density } \\
\left(\mathrm{kg} / \mathrm{m}^{3}\right)\end{array}$ & 1384 & 1384 & 1522 & 2768 & 7800 \\
\hline $\begin{array}{l}\text { Specific } \\
\text { Strength }\end{array}$ & $1.8 \times 10^{6}-4 \times 10^{6}$ & $1 \times 10^{6}-1.8 \times 10^{6}$ & $363,640-636,360$ & 350,000 & 200,000 \\
\hline $\begin{array}{l}\text { Specific } \\
\text { Stiffness }\end{array}$ & $\begin{array}{l}200 \times 10^{6}- \\
1,000 \times 10^{6}\end{array}$ & $160 \times 10^{6}-200 \times 10^{6}$ & $18 \times 10^{6}-27 \times 10^{6}$ & $100 \times 10^{6}$ & $100 \times 10^{6}$ \\
\hline CTE (in/in-F) & $-1 \times 10^{-6}-1 \times 10^{-6}$ & $1 \times 10^{-6}-2 \times 10^{-6}$ & $6 \times 10^{-6}-8 \times 10^{-6}$ & $13 \times 10^{-6}$ & $7 \times 10^{-6}$ \\
\hline
\end{tabular}

The graphite fibers are made of an organic polymer such as Polyacrylonitrile (sometimes called carbon fibres). The material is drawn into fibers and held under tension as it is heated at a high temperature $\left(>1000^{\circ} \mathrm{C}\right)$. The two-dimensional carbon-carbon (graphite) crystals are formed when hydrogen is extracted. Table-1 shows the carbon-carbon chain (3-D carbon crystal) has exceptionally high characteristics and excellent mechanical properties than those of aluminium and steel traditional materials.

The literature review is focused on the different types of analysis such as static, bucking \& free vibration analysis of composite plates and shells. Flat-panel, curved panel and cylindrical shells are taken for the study. 


\section{$7 \quad$ Static analysis}

Parametric studies on laminated plates to measure the maximum deflection are included in the static analysis. Parametric analysis described variance in aspect ratio, layer orientation, layer number, plate size and mesh size. Orthotropic materials in the area of modern industrial technology are of significant importance and concern. These materials may be exposed to cracks or ruptures during their service period and under the impact of external effort, which can cause a disaster in their construction. To avoid these types of problems, the analysis of these materials is necessary.

\subsection{Static analysis of flat panel}

Rakesh et al. [18] presents a stress analysis using ANSYS for composite laminated graphite/epoxy plates. A study carried on square plates starting with 2 to 10 layer $45^{\circ}$ symmetric angle ply \& clamped boundary condition. Conclusions drawn from the study are: first principle stress in the anti-symmetric angle ply, however, the failure at the support is responsible as the number of layers increases. The second and third theory strains in the anti-symmetric angle ply for a given failure load are responsible for a failure in the center with a high-stress level but as the amount of layer increases its impact decreases. The stress component of shear stress antisymmetric ply failure load is responsible for the de-lamination of the middle layer; it does not cause the top or bottom failure. The increase of the layers also did not impact it. The axial and radial component stress is responsible for side failure in axial and radial directions for a given failure load in the anti-symmetric angle ply. The stress on the component lateral direction is responsible for an anti-symmetrical angle ply failure with a well-defined stress contour for the lateral failure in the direction. Yenda Kesava Rao et al. [19] presents a graphite/epoxy composite plate stress analysis with ANSYS on different ply locations $\left(0^{0}, 30^{\circ},-45^{\circ}\right)$. The impact of stress on laminated, composite plates with tension was observed. Results showed that if ply location is at the bottom, the stress in the radial direction and shear stresses are minimal. The optimum orientation of the composite lamina is $30^{\circ}$ for load application in the axial direction. The radial stress is minimum at $45^{\circ}$ and for the shear stress minimum at 150. This indicates the load carrying properties change with the ply orientation of the composite for the same loading conditions. N. Moubayed et al. [20] presents a simplified model of an orthotropic plate that is subjected to load distributed evenly. This model is based on the theory of laminates, which neglects the effects of thickness shear. It is used for calculating the displacements and their distribution at the plate center. The analysis reveals that material parameters control the static behavior. Niral R.Patel et al.[21] analyzed the static analysis of composite laminated plates with different boundary conditions and for various loads. Stress results obtained from MATLAB numerical analysis of FEA compared with ANSYS and found close agreement. Junaid Kameran Ahmed et.al [22] carried out the static and dynamic analysis of graphite/epoxy composite plates using ANSYS, and the results were compared with the developed code of the FEM. The results obtained from the ANSYS program and developed FE code show a good agreement with experiments. The minimum deflection was found for the clamped plate with a ply orientation angle of $15^{\circ}$ and the minimum deflection was found for angle $45^{\circ}$ when the plate was simply supported. In the isotropic plate, the deflection in the clamped plate is about $50 \%$ simply supported and for the orthotropic plate, the deflection for the clamped plate is about 25 to 30 percent simply supported. J. S. Kalyana Rama et al. [23] described the minimum length required for the modeling, with a uniform 3D finite element analysis, of the infinitely long FRP plate laminated under cylindrical curvature, with two different end conditions. It is concluded that a length of $250 \mathrm{~mm}$ is enough for the analysis of a laminated graphite-epoxy plate of four layers of symmetric and anti-symmetric fibres. The deflections will increase with the increase in thickness ratio as the thinner plates produce large deflections. R. R. Singh et al. [24] analyzed stiffened isotropic and composite plates using finite element technique. Concluding remarks are made as the beight of the stiffener should not be increased beyond six times the thickness to reduce the deformation. Stiffener having a lower thickness gives almost equal deformation to that of a higher thickness stiffener having a more or less equal volume of material. The maximum composite plate deformation is approximately 1.5 to 2.5 times that of the isotropic plate. On the lower side, the maximum stress in the composite plate is that of the isotropic 
plate. Rahul Patwa et al. [25] done mathematical modeling of a four-layered cross-ply composite with six layers. The interesting fact is that with an increase in the number of laminas the stress and deflection bearing capacity increases. Also, the failure load is being increased by about $40 \%$ on adding two laminas in the four-layered crossply laminate. It is also seen that on variation in stacking pattern the stress and deflection patterns are varied despite the same number of laminas. Hence the stacking pattern is an important characteristic while designing the composite plate. Woraphon Niamnin et al. [26] carried out a numerical investigation on symmetrical bending of uniformly strip loaded square plates with different boundary support conditions using ANSYS. From the obtained results, it is clearly seen that there are zero deflections along the plate edges supported by simple and clamped supports. In the case of the plates having clamped edges, there are also no rotations of the plane normal to those edges. G.C.Mekalke et al. [27] studied the stress and displacement of the rectangular plate circular hole subject to uniform stress that is the impact of an initial stretching plate using the finite element method. The plate with a circular hole was analyzed under uniform stress and the results obtained through different meshes. It is observed that there is a variation in results through different meshes. The symmetrically balanced mesh gives a symmetrical response on the plots, but the other mesh does not provide the desired symmetry of the solution. Thus, a mesh convergence test should be performed to achieve accurate results. Riyah N.K et al. [28] presents an experimental and theoretical study of the impact of cutouts on the stress and strain of dynamically mounted composite laminate sheets. A numerical study was carried out by the ANSYS with static analysis methods of symmetrical square plates with various cutout types. Compared to numerical results, the experimental results show good agreement. Increasing numbers of layers reduce the value of normal strain at both the circular and the square holes in a symmetric plate, the lamination $\left(30^{\circ}\right)$ is the maximum stress value, with the maximum strain value $\left(50^{\circ}\right)$, subject to a single axially applied load. It is also reported that the hole dimensions to a width of plates ratio have an effect on one maximum value of stress and strain on the edge of the hole. The value of maximum stress \& strain increases with the order of type of circular, square, triangular, and hexagonal cutout. Victor Debnath et al. [29] studied the maximum deflection and von-misses stress analysis of the beam and cantilever beam simply supported in two different load types. The theoretical equations are based on the general beam equation of Euler-Bernoulli. ANSYS is used for computational analysis. Concluding remarks are element 189, which is the best element to perform a beam analysis rather than a 188 element and other solid elements 285. Vanam B. C. L et al. [30] analyze a static analysis of a rectangular isotropic plate under different boundary conditions and load applications by finite element analysis. The results of the FEA and ANSYS (Kirchhoff plate theory) have been compared to exact solutions and showed that closed matching. M.L. Pavan Kishore et al. [31] study of stress analysis of isotropic rectangular and square plates with a variety of centered cutouts by ANSYS software. Numerical studies have been conducted to investigate the effects of variation on the shape of the cutout, the location geometry, and the value of the maximum stress in the plate under uniformly distributed pressure with simply supported and clamped free boundary conditions. The adapted numerical scheme can be used to evaluate the concentration of stress and to determine the distribution of stress in isotropic and laminated plates. Sridhara Raju et al. [32] generated a 3D finite element model using ANSYS with a boundary condition for the evaluation of deflection, normal, and shear stress. A four-layer symmetric skew of bi-directional FRP laminate with a circular cut at the geometric center with clamped edges and uniform pressure added to the top surface for seven different thickness ratios (the ratio of the airfoil's maximum thickness to the station's chord) is studied for this reason. The magnitude of normal stress, shear stress, and deflection increase with an increase in the thickness ratio due to a decrease in the stiffness of the plate. The magnitude of both normal and shear stress is observed to be higher for linear analysis compared to nonlinear analysis, so for an optimum design of the nonlinear analysis structure is essential. Abdul Siddique shaik1 et al. [33] have done stress analysis around the circular hole, made up of different materials using ANSYS software. The rectangular plate with a central hole is analyzed using carbon epoxy with different fiber angles such as $0^{\circ}, 30^{\circ}, 45^{\circ}, 60^{\circ}, 90^{\circ}$ and the better fiber angle was found to determine the stress concentration. Results show that the maximum stress concentration always occurs at the boundary of the hole in a finite width plate with a central hole under static loading in the plane. It is found that $30^{\circ}$ fiber is the optimum fiber where the stress concentration factor is lower than the other fiber 
angles. Where $0^{\circ}$ holds good in stress and $90^{\circ}$ in deflection when it comes to other angles. Nitin Kumar Jain [34] analyzed the impact by $\mathrm{D} / \mathrm{A}$ (where $\mathrm{D}$ is hole diameter and $\mathrm{A}$ is flat width) of the stress concentrations factor (SCF) and deflection at transverse static loading on isotropic and orthotropic plates. The analysis is made of two different orthotropic materials and isotropic plates. The results are obtained using ANSYS for three different boundary conditions. In an orthotropic plate, the SCF for all stresses with respect to D/A ratio is achieved more compared to the isotropic plate for the respective boundary conditions. It is also observed that variation of SCF for all stresses with D/A ratio highly depends on elastic constants and differs from material to material. K. Kalita et al. [35] studied variation in deflection and stresses with a change in $\mathrm{d} / \mathrm{W}$ (diameter of circular cut out / width of the rectangular plate) and $\mathrm{b} / \mathrm{W}$ (side length of square cut out/width of the square plate) ratio for steel (isotropic material) as compared to e-glass/epoxy (orthotropic material) using ANSYS software for four different boundary condition. It is also investigated the effect of orienting the square cut out with a positive X-baseline. It is concluded that maximum shear stress occurs at the cut-out periphery in all boundary conditions and that maximum deflection is seen near the cut-out and reduces to the constraints. For all plates, the variation of stress concentration factor (SCF) is more in the orthotropic plate compared to an isotropic plate. Overall, with an increase in the inclination of the square cutout from the X-base line, $\sigma_{\mathrm{x}}$, and $\sigma_{\mathrm{y}}$ increase and is maximum at $45^{\circ}$, but with an increasing inclination for isotropic plates, $\sigma_{\mathrm{xy}}$ decreases. Gururaj.M.Kumbar et al.[36] analyzed the fuselage panel to carry out static analysis due to the varying loads. It can be concluded that the displacement occurring in the fuselage panel is minimal for all loading conditions and has no significant effect on the integrity of the panel. The linear static analysis of the panel shows the panel crosses the yield strength of the considered material for specified loads and with modification to the panel reduces the stress which is within material yield strength. Ramindla Praveen et al. [37] examined the structural effectiveness of the designed wing made of various material (Al-Zn-Mg alloy 7178, aluminum-lithium AL8090 and alpha-beta combination (titanium) alloy) through 3-D finite element analysis using ANSYS to compute the critical stresses, displacements, strains and compare against Von- Misses failure criterion. V. J. K. Silpa et al. [38] studied the structural response of a thin plate with a circular hole to different boundary conditions. The effect of parameters like d / w ( hole diameter to plate width), hole location and conditions of support is presented for isotropic and orthotropic material on stress factor concentration. The study concludes that an increase in the $d / w$ ratio leads to an increase in the deflection ratio due to a decrease in the material's stiffness. Furthermore, it was observed that the stress concentration factor decreased with the increase of the $d / w$ ratio. Trung Thanh Tran et al. [39] present numerical results of static analyses of the functionally graded porous (FGP) variable-thickness plates by using mixed interpolating of tensorial component technique for a three-node, triangular element (MITC3), called ES-MITC3, is associated by the use of an edge-based smooth finite element method (ESFEM). It is inferred from the study that the maximum deflection is near the thinner thickness, and far from the thicker thickness. This shows that varying plate thickness has major effects on the FGP plate's static bending response.

\subsection{Static analysis of curved panel}

Minh Tu Tran et al. [40] carried out an analytical solution for static analysis of stiffened cross-ply laminated composite doubly curved shallow shell panels resting on the elastic foundation with the simply supported boundary condition by using first-order shear deformation theory. It investigates the impact of the number of stiffeners, the height-to-width ratio of stiffeners, and the number of layers of laminated composite shells on stiffened shell deflections with and without elastic foundation. The findings of this analysis show that the deflection of shell panel with orthogonal stiffeners (both cylindrical shell panel and spherical shell panel) is the smallest (stiffest) if the height-to-width ratio of the stiffener decreases. The elastic foundations increase the deflections of the stiffened, doubly curved shallow, cross-laminated composite shell. Anusha Gampala et al. [41] to find the maximum stress during fatigue load testing of aircraft by using finite element analysis (FEA). A beacon light hole on a plane's fuselage is used in this work. From the analysis, it is concluded that linear static analysis of a curved shell without hole for axial tension loading case along with 
pressure and found that the stress within the allowable limit. Linear static analysis of curved shell with hole is carried out for the tension load case together with the pressure and the stress within the permissible limit was found. Linear static analysis of curved shell with a hole and doubler, and found stress to be within the permissible limit. Analysis of doubler is done and the stresses induced in the doubler are found to be within the allowable limit. Analysis of fastener is done and is found that it is within the limit. M. Cinefra et al. [42] carried out the linear static study of composite shell structures of double-curvature geometry utilizing a shell finite element of variable kinematic through-thickness. Cross-layered spherical shells are simply analyzed with supporting edges and under bi-sinusoidal pressure. It considers different laminations, thickness ratios and curvature ratios. From the study, it can be inferred that the CUF-based shell dimension is very effective and mandatory in the study with respect to the classical models of composite structures. In order to provide FEM benchmark solutions, shells with different lamination, boundary conditions and loads are also analyzed with theories of high-order layers.

\subsection{Static analysis of cylindrical shell}

P.Dongare et al. [43] analyzed a composite drive shaft for power transmission applications. Static analysis is done using FEM to construct a regression equation. Conclusions made are shear stress in the layer increases up to $45^{\circ}$ orientation, then decreases till $90^{\circ}$ and then again starts increasing; it shows sine nature of the graph. Thus shear stress decreases in other layers until $45^{\circ}$, then increases until $900^{\circ}$ and then starts to decrease again; it reveals the cosine structure of the graph. Deflection in each layer remains the same for any angle of orientation; it decreases till $45^{\circ}$ then increases for $90^{\circ}$ and $0^{\circ}$. By doing regression analysis they have obtained relations between stress and fibre angle orientation and deflection. K. Chandrashekhara et al. [44] found an exact solution for a thick, transversely isotropic, simply supported, circular cylindrical shell undergoing axisymmetric loading by means of a displacement functional approach. The numerical results have been obtained for single- and three-layered shells to show that the approximate solution is valid for mean-radius to thickness ratios greater than 5 and that the displacements and stresses in each layer of the shell are influenced by elastic constants of the material and the thickness of the shell. S. Mahmoud Mousavi et al. [45] deals with the bending analysis by Differential Cubature method (DCM) of laminated cylindrical panels. The proposed formulation allows for the treatment of any kind of lamination, whether symmetrical or unsymmetrical and any combination of clamped, simply supported and free boundary conditions on the edges. The results show that DCM can provide reasonably reliable predictions with relatively few grid points, which can, therefore, require less computational time to a precise level than other numerical techniques. For all stress and displacement variables in the solution domain, the same order of precision is given. In comparing the calculated stress results with the displacement components, the results obtained using other analytical and numerical techniques show good consistency.

\section{Buckling Analysis}

The static stability or buckling of mechanical, civil engineering structures under compressive loading has always been an important field of research. Buckling is a highly severe phenomenon for structural components because buckling of composite plates typically occurs at lower applied stress (less than ultimate strength) and induces significant deformation in turn cause severe damage in the structure. This led to literature study in past work to know composite buckling behaviour, which are summarised below.

\subsection{Buckling analysis of flat panel}

Leissa [46] provided a thorough overview of the large number of papers available that are relevant to the stability of composite plates and shells. P. R. Reddy et al. [47] determined the impact on buckling actions of square and rectangular of a 4-ply orthotropic carbon/epoxy symmetrically laminated rectangular composite plate using ANSYS for $\left[0^{\circ} / 45^{\circ} / 45^{\circ} / 0^{\circ}\right]$ orthotropic laminate configuration. Results showed that the magnitudes of buckling loads decrease with increasing positioned angle of a cutout, as well as $\mathrm{c} / \mathrm{b}$ (length of rectangular cutout/breadth of the rectangular plate) and $\mathrm{d} / \mathrm{b}$ (breadth of rectangular 
cutout/breadth of the rectangular plate) ratios for rectangular cutout plates. The size of the buckling loads of a rectangular composite plate decreases with an increase in the plate aspect ratio (a/b) A.George et al. [48] compared the critical buckling load of the laminated composite plate by changing the cutout shapes of the laminate's optimized fiber orientation by numerical means. Composite laminated plate with rectangular and square cutout shows a decrease in buckling load carrying capacity compared to circular cutout plates. The maximum buckling load combination was obtained with fibre orientation $0 \% / 90^{0} / 15^{0} /-15^{0} / 15^{0} /$ $15^{\circ} / 0^{\circ} / 90^{\circ}$ with circular cutout. With an increase in fibre angle in the inner layers, the buckling load increases. K.M.Reddy et al. [49] done a buckling analysis of laminated composite plates under uniaxial and biaxial compression load using ANSYS. Parametric studies carried out through FEA in order to understand the effect of side-to-thickness ratios, aspect ratios, modulus ratios, ply orientation, and boundary conditions on non-dimensionalized critical buckling load for three different materials. The numerical results showed that shear deformation has the effect of decreasing the non-dimensionalized critical buckling load with decreasing side-to-thickness ratio and modulus ratio under uniaxial compression. As the aspect ratio increases, the effect of uniaxial compression of the bending-extensional twisting stiffness is to reduce the critical buckling load. Prabhakaran.V et al. [50] carried out numerical and theoretical analyses on the buckling and tensile/compressive load behaviour of thin CFRP rectangular plate without hole using ANSYS. Three different types of composite structures: a rectangular plate without a hole, a rectangular plate with a hole, and the thin cylinder were analyzed were carried out to model the size of structures. It was noted that the buckling load/ unit length decreases with increases of length to thickness ratio of plate and cylinder. Further, noted that the buckling load/ unit length gradually decreases with increases of diameter to width ratio of the plate with a bole. The results from this study indicate that numerical modeling can be used to evaluate the buckling strength accurately, provided the material properties, and geometrical details properly modeled. Nagendra Singh Gaira et al. [51] carried out the buckling analysis of laminated rectangular plates with clamped-free boundary conditions for different aspect ratio, $\mathrm{d} / \mathrm{b}$ (diameter of cutout/width) ratio \& $\mathrm{d} / \mathrm{D}$ (diameter of small multiple cutouts/diameter of central cutout) ratios. The results are the reduction of the buckling load factor, with an increasing aspect ratio, an increase in the buckling load factor, an increase of the $\mathrm{d} / \mathrm{b}$ ratio, and an increase in the $\mathrm{d} / \mathrm{D}$ buckling load factor. It is noted that the presence of cutout lowers the buckling load. A. Joshi Gowri Sankar et al. [52] carried out buckling analysis of laminated carbon/epoxy with clamped-free boundary conditions considering various parameters such as varying aspect ratio, varying thickness to breadth $\mathrm{t} / \mathrm{b}$ ratio, cut out the shape and multiple holes and effect of stress concentration. It has been reported that the buckling factor was noted to decrease with increases in aspect ratio. The presence of the center hole causes the factor of buckling decrease and the concentration of stress zones increase. The incorporation of multiple holes causes buckling factor to decrease and stress concentration zones to decrease. Ahmed Hassan et al. [53] have done a buckling analysis of both isotropic and functionally graded rectangular plates with various boundary conditions and meshing of plate structure using ANSYS. The results obtained from ANSYS are compared to analytical solutions based on different plate theories and the theory of 3D elasticity. Shell281 element models are less sensitive to mesh density and are more accurate compared to the shell181 element model. Solid model of solid shell elements has precise solutions close to shell models for thin plates, but its solutions are higher for thick plates than other solid models while being significantly lower than shell models and closer to solutions based on 3D elasticity theory. R J Fernandes et al.[54] have done buckling analysis of laminated composite plate using ANSYS and the results compared with published literature. The critical buckling load obtained for cross-ply laminated composite plate subjected to uniaxial and biaxial compressive loading, varying aspect ratio $(\mathrm{a} / \mathrm{b}=$ 0.5 to 1.5$)$, length to thickness ratio $(\mathrm{a} / \mathrm{h}=10$ and 100$)$, and orthotropic ratio $\left(\mathrm{E}_{\mathrm{L}} / \mathrm{E}_{\mathrm{T}}=10\right.$ to 40$)$. The critical buckling loads keeps on increasing as the orthotropic ratio increased for all combinations of boundary conditions and varying aspect ratio. It is also observed that the critical buckling load of the CCCC boundary condition is higher than the other and the critical buckling load with SSSS boundary condition is least. S. Prashanth et al. [55] studied the behaviour of composite twisted plates. Studies on twisted plates show that the buckling load increases as the aspect ratio increases for simply supported plates and decreases for cantilever plates but the nonlinear buckling load is less than the linear buckling load. It is also observed that the buckling load increases in the same aspect ratio for a 
laminated twisted composite plate with a decrease inside to thickness ratio. Further, buckling load decreases as the angle of twist and aspect ratio increases. With number of layers, for the same angle of twist buckling load increases, and for symmetric ply layup. Dilu Riswana C et al. [56] studied buckling response of laminated composite plates with different boundary conditions, aspect ratio, varying width to thickness $\mathrm{b} / \mathrm{t}$ ratio, cut shape, and changing hole locations are considered. It concluded that buckling load increases as $\mathrm{L} / \mathrm{t}$ (length/thickness) ratio decreases and the presence of cut-out lowers the buckling load. The buckling load decreases as the number of layers decreases. Similar conclusion of [51] pointed out i.e. the buckling load also increases as the $\mathrm{E}_{\mathrm{L}} / \mathrm{E}_{\mathrm{T}}$ ratio increases. Changes in buckling load are seen with modification of cut-out shapes. The buckling load comes out to be the maximum for circular cutouts. Pavol Lengvarsky et al. [57] studied the buckling behaviour of the rectangular composite plates with four different layer orientations and three, six, and twelve layers using the finite element method. The computed critical buckling loads for all configurations showed that critical buckling load increases with increasing numbers of layers as well as composite plate thickness. All layer orientations and the number of layers slightly affect the value of critical buckling load \& buckling. Madhu Kumar M et al. [58] proposed buckling study of the S-glass/epoxy laminated composite plate with certain assorted cutouts such as square, circular and rectangular with various parameters using experimental and finite element study. As seen from the above results the buckling characteristics of S-glass epoxy laminated composite are affected by the cut-out dimensions as then of the loading conditions and values. It is clearly observed that the composite reinforced by S-glass fiber acts as a brittle material, and when subjected to uniaxial compression loads it does not go further in elongation. Lakshmi Narayana et al. [59] examined the influence on the bending action of a 16 ply symmetrically laminated composite rectangular symmetric graphite/epoxy rectangular composite plate $\left[0^{\circ} /+45^{\circ} /-45^{\circ} / 90^{\circ}\right]_{2 S}$ with a square/rectangular cutout on boundary conditions and on various linear in-plan compressive loading conditions. The following conclusions are drawn: The magnitudes of buckling loads are decreased for a rectangular composite plate with rectangular cutout by increasing the cutout orientation angle $\beta$ from $0^{0}$ to $90^{\circ}$. The magnitudes of buckling loads are reduced for a rectangular composite plate with a square cut out by increasing the cutout orientation angle $\beta$ from 0 to 45 and by increasing the cutout orientation angle $\beta$ from $45^{0}$ to $90^{\circ}$. The effect of cutout orientation $\beta$ on buckling of the rectangular composite plate increases with increasing cutout size. Torabizadeh [60] presented a mechanical loading solution for generally laminated plates based on different plate theories of laminate. A finite element code was also developed as a verification method with ANSYS. Finally, it was found that in all cases, finite element outputs were in good agreement with theoretical analysis results. The non-dimensionalized buckling load increases for symmetric laminates, while it decreases under uniaxial and biaxial compressive loads for antisymmetric laminates as the modulus ratio increases. In the case of antisymmetric angle-ply square laminates under uniaxial compression and biaxial compression, the bending-stretching coupling severely reduces the buckling load for the two-layer plate. M. Aydin Komura et al. [61] studied circular/elliptical opening of woven-glass-polyester board composite laminate. In the analysis, a parametric study was performed using the finite element method (FEM) based on the shape and position of the elliptical hole on the various plate. Results show that buckling loads are reduced by increasing both c/a (Minor axis of ellipse / height) and b/a (Major axis of ellipse / height) ratio and increasing the positioned angle of the hole causes buckling loads to decrease. The cross-ply composite plate is also stronger than any other angle-ply laminated plate analyzed. Ravi Kumar Pa et al. [62] conducted a thorough analysis of stiffened and unstiffened plates with three various types of composite materials to determine the buckling load by the ANSYS software. It is concluded from the result that $\left[0^{\circ} / 90^{\circ} / 45^{\circ} /-45^{\circ}\right]$ fibre configuration yields the highest load, as the length to thickness ratio increases the load decreases, as the aspect ratio increases the critical load increases and critical load decreases in presence of cut-outs. It was also observed that by increasing the number of stiffeners on the stiffened plate, buckling load continues to increase, T-shaped stiffened plate maintains maximum buckling load, and with a single stiffener in the center of the plate gives constant buckling load to all material. Z. Y. Han et al. [63] conducted a buckling analysis to investigate the composites with holes and geometric imperfections subject to compression loading in response to variableangle laminated plates. ABAQUS is used to create models for laminates of variable orientation with and 
without central holes. Results show that the maximum in-plane stress of variable-angle laminates is significantly reduced, and the buckling load is significantly increased. The central holes have an influence on stress concentration and buckling behaviour. Buket okutan baba [64] examined the effect of bending stress on the different cut-off shapes, the length/density ratio, and the rectangular plate orientation. Numerical and experimental studies performed with ANSYS under the in-plane load of compression. It is noted that the cut-out presence reduces the buckling load. The buckling load decreases as the $\mathrm{L} / \mathrm{t}$ ratio increases. The buckling load reduces as the angle of the fibre increases. The clamped boundary conditions exhibit the highest buckling load in the context of considered edge conditions. A comparison of finite element results with test results indicates that the maximum difference between the predicted buckling load and the measured buckling load is within $39 \%$. Murat yazici [65] calculated buckling loads with or without square perforation by experimental, calculation and theory approach clearly under simply supported boundary conditions. The influence of the hole angle, the filet hole corner radius, and the hole height, as well as the angle of fibre orientation, was also investigated using FEM. Results can be summarized as for the $0^{0}$ reinforced composite plates, only a few differences were obtained between FEA, experimental, and analytical results. Buckling loads by variation of the hole angle fillet radius do not show a crucial difference. The direction angle of the hole does not affect the buckling loads. By increasing the fibre orientation angle, the buckling loads of plates are reduced. Fiber-reinforced $0^{0}$ reinforced composite plates are more sensitive to hole size and angle orientation parameters than the others. By increasing the size of the cut-out, loads of buckling obviously reduce. Gururaj. M. Kumbar et al. [36] modeled, discretized, and analyzed fuselage panel to determine its buckling strength due to the varying loads. Dhiraj Patil et al. [66] presented an experimental study based on buckling behaviour of industry-driven woven fibre composite panels for different layer thicknesses. It has been observed that buckling loads increased with an increase in the number of layers of carbon fibre in CFRP plates. Plies possessing a higher modulus of elasticity when present on the outermost layer, gives maximum buckling load. V. J. K. Silpa et al. [38] examined the structural response of a thin plate with a circular hole to specific boundary conditions. The response of the plate is studied by performing the buckling analysis. For isotropic and orthotropic materials, hole location \& boundary conditions, the impact of parameters such as $\mathrm{d} / \mathrm{w}$ (hole diameter to plate width) on buckling load is indicated. It was observed that the factor of buckling load decreased with the increase of the $\mathrm{d} / \mathrm{w}$ ratio. J. N. Reddy et al. [67] developed analytical and finite-element solutions of the classical, first-order, and third-order laminate theories to study buckling behaviour in different boundary conditions of cross-plying rectangular laminates. The impacts of side-to-thickness, aspect, and lamination ratios on critical buckling loads are being studied. The study concludes that shear deformation laminate theories predict composite laminates behaviour accurately, while classical laminate theory overpredicts buckling loads. Anish et al. [68] carried out a study with the use of improved shear deformation (ISDT) and $\mathrm{C}_{0}$ finite element formulations on a uni-axial and bi-axial buckling of the laminated composite plate with mass changes through cutout and an additional mass. The novel results are achieved by varying geometry, loading, boundary conditions and ply orientation. It can be inferred from the analysis that the CCCC (all sides clamped plate) boundary condition had the maximum non-dimensional buckling load values while CCFF had the lowest for laminated composite plates with additional mass at the central node. It was also found that the benefit for buckling loads was higher for higher lamination plies, independent of any boundary and loading conditions. The mode shapes for biaxial loading were often distinct from the uni-axial buckling while the mode form remained the same given the various observed values for specific values of bi-axial loading.

\subsection{Buckling analysis of curved panel}

Mark W. Hilburgeret al. [69] studied on non-linear and buckling response properties of the curved panels under combined load. The findings suggest that the non-linear and bending behaviour of the combined load panels can be influenced by the panel curvature. Results have shown that for some combined loads the geometrically perfect panels do not show bifurcations. Laminate orthotropy and anisotropy also influence the interaction of the combined loads. D. K. Biswal et al. [70] carried out static stability analyses 
of higher-order shear deformable doubly curved laminated shell panels and a general formulation is presented developed in the MATLAB. The proposed theory about shear deformation ensures that transverse shear strains are changed parabolically through the thickness of the shell and that body movement is rigid. The effects on the natural frequencies of shell panels of different parameters like the thickness ratio, curvature, orthotropic ratio, lamination scheme, number of flaps, boundary conditions and shell geometries are examined. The critical buckling loads are found to increase with an increase in thickness ratio, ratio of principal radii of curvatures, and orthotropic ratio, but exhibit a decreasing trend with an increase in aspect ratio and radii of curvatures. S. Pradyumna J et al. [71] performed buckling analysis for cylindrical (CYL), spherical (SPH), hyperbolic paraboloid (HPR), hypar (HYP), and conoid (CON) shell panels made of FGMs. In the case of a buckling analysis, the shell panels are under a uniaxial compressive load and are also subject to a temperature field. The characteristics of FGM are regarded as temperaturedependent and are graded to a thickness level by the simple distribution of power-law components in terms of volume fractions. The effects on the free vibration of geometric characteristics, material composition, and boundary conditions are investigated. The results show that with an increase in the volume fraction index, buckling load decreases for most shell panels and boundary condition. The CL boundary condition shell panels provide the highest buckling load values, followed by SS and CS boundary conditions of shell panels in all five shell panels.

\subsection{Buckling analysis of Cylindrical shell}

T Subramani et al. [72] carried out finite element analysis to find buckling strength of cylindrical and elliptical structures using ANSYS for fixed-free boundary conditions. The results show the closeness of linear and nonlinear buckling loads at the lesser thickness and large difference for higher thickness members. Prabhakaran et al. [50] carried out numerical and theoretical analyses on the buckling and tensile/compressive load behaviour of thin CFRP rectangular plate without hole using ANSYS. It was noted that the buckling load/ unit length decreases with increases of length to thickness ratio of the cylinder. It was seen that although the tensile stress increases with increases of length to thickness ratio of the cylinder. The results from this study indicate that numerical modelling can be used to evaluate the buckling strength accurately, provided the material properties and geometrical details properly modeled. Dongare et al. [43] analyze a composite pulley shaft for applications of power transmission. The buckling analysis is conducted using FEM. A composite drive shaft analysis is performed to understand the fibre orientation and effect of the drive shaft 's load carry capacity. They have established relationships between stress and the fibre angle orientation and deflection by means of regression analysis. The fibre orientation angle has a torque effect which can be concluded from the buckling analyzes. Hamidreza et al. [73] carried out buckling analysis to investigate the response of laminated composite cylindrical panel with an elliptical cutout subject to axial loading using the Abaqus finite-element software. The influence on the buckling load of the composite cylindrical composite plate, the location and size of the cutout and even the composite ply angle is examined. Finally, the least square regression approach was used to present simple equations, in the form of a buckle load reduction factor. The results provide valuable information on the design of a laminated cylindrical composite panel, which can increase cylindrical panels' load efficiency.

\section{Free Vibration Analysis}

In the aerospace and automobile sectors, the study of vibration in laminated plates plays a significant role in the applications of structural composites. A large number of analytical and numerical studies on the vibration of composite flat, curved plates, and cylindrical shells are available in the literature. Some of the literatures are briefly summarized as follows:

\subsection{Free Vibration Analysis of flat panel}

A considerable amount of analytical models and numerical analyses are reported and reviewed extensively by Leissa [74], Kapania [75], Liew, Xiang \& Kitipornchai [76] and Zhang and Yang [77]. Ajay Landge et al. [78] have done vibration analysis of a laminate structure with different material configuration using ANSYS 
software. At the orientation $0^{0} / 45^{0} / 45^{\circ} / 0^{0}$, for simply supported condition natural frequency was shown higher. For 6 fracture modes, the natural frequencies of free and forced vibration are taken for different composite materials such as glass fibre, honeycomb, and carbon-ud (carbon unidirectional). When comparing these three materials, carbon (UD) shows maximum natural frequency values for all 6 modes. The natural frequency of a laminated composite plate is minimum in the centre of the plate in a simply supported condition. The maximum shear stress for forced vibration of glass fibre, honeycomb \& carbon-ud is achieved at 3000 $\mathrm{Hz}, 5000 \mathrm{~Hz}$ and $1000 \mathrm{~Hz}$. Hence carbon- ud have the lowest natural frequency with respect to maximum shear stress. Devidas R. Patil et al. [79] have done vibration analysis of a composite plate at different boundary condition using ANSYS. Three-ply laminates have been considered and results are compared with the isotropic plate. On the basis of present study conclusions drawn are for isotropic plate and threeply laminates natural frequency increases with an increase in mode number and constraints. Of all the tested boundary conditions natural frequency is lowest for a cantilever plate (CFFF) and highest at all sides clamped plate (CCCC). The natural frequency increases with a decrease in $B / A$ (length / breadth) ratio and increases with increase in $h / A$ (thickness / breadth) ratio. Thicker the plate more the natural frequency. C Naveen Raj et al. [80] studied the dynamic response of composite plate with different stacking sequences and different boundary conditions with single delamination using ANSYS. The results presented compare well with those present in the literature, numerical results show how the increase in the number and sizes of delaminations and other parameters affects the first natural frequency and dynamic response of delaminated composite plates. Results show that an increase in the number and sizes of delaminations generally has a deteriorating effect on the dynamic stiffnesses of the plate. The $\left(0^{\circ} / 90^{\circ}\right)$ laminates are weaker compared to angle-phy laminates of $\left(30^{\circ} /-\right.$ $\left.30^{\circ}\right),\left(45^{\circ} /-45^{\circ}\right)$. Pushpendra and k. Kushwaha et al. [81] calculated numerical results on the effect of the number of layers, plate thickness ratio, various boundary conditions, different aspect ratios and different fibre angles on a laminated composite plate. The non-dimensional fundamental vibration frequency is observed to, increase with an increase in fibre orientation angle and number of layers, but decrease with an increase in aspect ratio and thickness to width ratio. The non-dimensional fundamental vibration frequency of the clamped plate is higher than that of the plate simply supported plate. Rajawata et al. [82] used the finite element approach to show the free vibration study of the laminated plate. As eccentricity increases, the natural frequency of the rigid laminated plate also increases significantly in each mode. The natural frequencies for the cross-ply eccentrically stiffened laminated plates is higher than the angle ply eccentrically stiffened laminated plates. Similarly, the natural frequencies for the symmetric ply eccentrically stiffened laminated plates is bigher than the anti-symmetric eccentrically stiffened laminated plates. Ahmadian et al. [83] analysed forced vibration of a laminated composite rectangular plate with orthotropic \& symmetric, cross-ply using super element (less run time than conventional FE method). The maximum amplitude response of plates with the same load amplitude under static and dynamic load may change drastically depending on the non-dimensional frequency. Satyendra Singh etal. [84] presented the vibration analysis of orthotropic laminated composite plate using ANSYS finite element software. The free vibration of a laminated composite plate analyzed with different layers for different boundary conditions. It is observed that free vibration increases irrespective of the boundary condition applied. Pushparaj et al. [85] determined the natural frequencies and mode of a number of GFRP and CFRP using ANSYS. It is found that the natural frequencies for CFRP composite plates higher than for GFRP composites. As the fibre volume fraction increases, the natural frequencies which correspond to a given mode also increase. In the case of GFRP composite plates, the natural frequencies of laminates with epoxy or vinyl ester as the matrix material are almost the same. Hybrid E-glass T300 carbon/epoxy plates have a higher natural frequency than the E-glass / epoxy plates, but lower than that of T300 carbon/epoxy plates. Ibtehal et al. [86] used ANSYS to do nonlinear free vibration study of carbon laminated composite thin plate. The results of nonlinear analysis for natural frequency are close to those of linear. The increasing number of plies causing the basic natural frequency of unsymmetric cross-ply laminate to rise. The results show a good agreement between nonlinear analysis and experimental work, showing maximum discrepancy for symmetry and unsymmetry. Mohammed Salih et al. [87] studied free vibration response of composite perforated plates with a symmetric angle ply using ANSYS. Conclusions drawn are that the plate with one hole has higher frequencies 
than a perforated plate and the frequency decrease with a higher hole. All edges clamped (CCCC) boundary condition yielded more frequency magnitudes than all edges simply supported (SSSS) and SCSC (two opposite edges simply supported \& clamped) boundary condition for all range of lamination angles and area holes. The frequencies of perforated plates are reduced by increasing the area ratio of the holes. N Mishra et al. [88] studied free vibration characteristics of a sandwich plate in presence of cutout using the ANSYS. For the evaluation of numerical results, sandwich plates with symmetric cross-ply and anti-symmetric angle-ply composite facings separated by HEREX core (cross-linked PVC products) are considered. The results show that the basic sandwich plate frequency decreases with small to medium size cutout. The fundamental frequencies for a sandwich plate with cutout increase as the degree of constraint increases and are found to be higher for clamped edges compared to a plate with simply supported edges. Pandit et al. [89] developed nine-noded isoparametric plate bending components made of isotropic and fibre-reinforced composite plates. The numerical examples presented here include problems with cutouts from rectangular plates, distributed mass across its entire surface. It is stated that distributable mass plates, the frequencies of a plate as a structural element can be changed by locating the attached mass in such a way that the frequency of the excitation of the machine is far away from those of the plate. Manoj et al. [90] presented vibration and harmonic analysis of composite laminated orthotropic plates. Convergence study carried out and found a optimum mesh size. The non-dimensional fundamental frequency is observed to increase as the number of layers increases but the variation is negligible beyond five layers. It is observed that the resonance condition for CFFF (clamped one edge \& other edges free) is significantly variable compared to the other boundary conditions. As the thickness ratio increases the fundamental frequency increases, however the resonance amplitude value decreases for all boundary conditions. Prachi si et al. [91] carried out parametric study pertaining to the free vibration analysis of the laminated composite beam. The natural frequency comparison of laminated composite beams based on different boundary conditions and different laminated lay-up sequences with variation in the $\mathrm{L} / \mathrm{h}$ (length/height) ratio, $\mathrm{L} / \mathrm{b}$ (length/breadth) ratio and $\mathrm{E}_{\mathrm{L}} / \mathrm{E}_{\mathrm{T}}$ ratio was performed in the ANSYS. Sumit Khare et al. [92] have done 3D FEA for free vibration of thick laminated composite circular plates with clamped, simply supported and free boundary condition for different fiber orientation. Ganapathi et al. [93] investigated the anisotropic composite laminates for the free vibration features simply supported by an analytical approach. It can be concluded that the results calculated introducing the standard constant shear correction are found to be fairly in good agreement. It can also be noted that the bending-extensional coupling in the unsymmetrical laminates reduces the natural frequencies and the curvature effect increases the frequency values. The influence shear correction factor is more for thick laminates compared with thin case. Arafa [94] investigated the impact on free vibration response of stiffened composting laminates using ANSYS was investigated by stiffener design, number of layers and boundary conditions. They found, arrangement and configuration of stiffeners have significant effects on the free vibration response of stiffened composite laminated plates. As the number of stiffeners increase the natural frequency increase with the increase of the number of modes for all number of layers. The natural frequency for clamped supported are higher than that for the simply supported. Sharayu et al. [95] have done experimental works to investigate the free vibration of woven fiber glass/epoxy composite plates in free-free boundary conditions and validated the results with Ansys. The results of various parameters like the aspect ratio and fibre orientation of woven composite fibre plates are studied in free boundary conditions. The percentage of error between the experimental value and the ANSYS package is within 15 percent. It is found that the natural plate frequency increases with the increasing aspect ratio for free boundary condition. Natural frequency decreases as the orientation of the ply increases to $\left[45^{\circ} /-45^{\circ}\right]$ and increases again to $\left[30^{\circ} /-60^{\circ}\right]$. Ramindla Praveen et al. [37] done 3D finite element analysis with ANSYS has been performed for the designed wings. The aircraft wing made of alpha-beta titanium alloy is chosen and the modal analysis is done and the mode shapes is observed at various frequencies. Based on the results of the finite elements, the designed wing was found to be a safe alloy material for the airplane at titanium combination to perform its mission and meet all design requirements. Dhiraj et al. [66] presented a experimental study based on vibration measurement and of industry driven woven fiber composite panels for different layer thickness. From the experiments it was 
observed that the vibration frequency was found to be the highest for the fully clamped condition and the lowest for the cantilever boundary condition, which can be attributed to the increased stiffness of the supports. V.L.K. Silpa et al. [38] investigated structural response of a thin plate with circular hole with different boundary conditions. The response of the plate is studied by performing modal analysis. The effects of d / w parameters (hole diameter to plate width), position and supporting conditions on the natural frequency will be seen for isotropic and orthotropic materials. The study concludes that an increase in the $\mathrm{d} / \mathrm{w}$ ratio leads to an increase in the frequency ratio. Itishree Mishra [96] studied free vibration, buckling and parametric instability behavior of industry driven laminated woven fiber composite plates under harmonic in-plane periodic loads. Chai et al. [97] used TV holography technique to obtain the vibrational response of the unidirectional laminated carbon fibre-epoxy plates and carried out finite element studies simultaneously. Chakraborty et al. [98] determined the frequency response of GFRP plates experimentally and validated the results using commercial finite element package (NISA). The analytical values were compared with the experimental values obtained with fully clamped boundary condition. Holographic technique was used to study the modes and deflection. Hwang and Chang [99] used impulse technique for vibration testing of composite plates for determination elastic constants of materials and modelled undamped free vibration using ANSYS. Lei et al. [100] studied the effect of different woven structures of the glass fibre on the dynamic properties of composite laminates. J. N. Reddy et al. [67] developed analytical and finite-element solutions of the classical, first-order, and third-order laminate theories to study free vibration behaviour in different boundary conditions of cross-plying rectangular laminates. The results on the fundamental frequencies of the side to thickness ratio, aspect ratio, and lamination schemes are studied. The study concludes that shear deformation laminate theories predict the behaviour of composite laminates correctly, while the classical theory of laminate overpredicts natural frequencies. Trung Thanh Tran et al. [39] present numerical results of free vibration analyses of the functionally graded porous (FGP) variablethickness plates using mixed interpolating of tensorial component technique for a three-node, triangular element (MITC3), called ES-MITC3, is associated by the use of an Edge-based Smooth finite element method (ES-FEM). The influences on the natural frequency of the FGP variable-thickness plate of certain geometric parameters and material properties are examined. It has been concluded from the analysis that the mode form for the FGP vibration plate's thickness of variable is not symmetrical because the thickness is different at each position. The mode shape's maximum values are moved to a smaller thickness. M. Nasihatgozar et al. [101] presents a free vibration study of the orthotropic laminated composite plate using the theory of higher-order shear deformation and the concept of Hamilton with the appropriate kinematic relationships of small deformations. The structural frequency and mode shapes are achieved with the differential quadrature (DQM) process. Numerical results showed that the size of the structure is increased by increasing the centre to face sheet thickness ratio. In addition, higher and lower frequencies were predicted for both the CCCC and CFFF sandwich plates.

\subsection{Free Vibration Analysis of curved panel}

C.K. Hirwani et al. [102] studied nonlinear frequency response of the curved carbon/epoxy composite shell panels in the MATLAB and by modelling in ANSYS. Numerical examples for various geometrical configurations are solved and detailed effects on fundamental linear and nonlinear frequency responses of other design parameters (thickness, curvature ratio \& constraint condition) are discussed. Sarmila Sahoo [103] analyzed free vibration behaviour of laminated composite stiffened elliptic parabolic shell panels with a developed code. Cross and angle ply shells with different boundary conditions were investigated in different dimensions. Results obtained from code is in close agreement with benchmark problems. Eccentricity towards the simply supported edge is preferable for cross-ply shells, which is opposite to a clamped edge. For angle ply shells eccentricity towards the simply supported edge is preferable. Charu Lakshmi et al. [104] investigated free vibration behaviour of laminated composite cylindrical panels using ANSYS. The effects of different vibration response parameters, such as radius/side ratio, side by side thickness ratio and various laminates, are studied. It is found that the experimental values of the first three 
natural frequencies agree well with the finite element solution. The first non-dimensional frequency coefficient $\left(K_{f}\right)$ increases as the aspect ratio $(a / b)$ and side-to-thickness ratio $(a / t)$ increases. Similarly, the $\mathrm{K}_{\mathrm{f}}$ value decreases as the radius to side ratio $(\mathrm{R} / \mathrm{a})$ increases. Karthik et al. [105] presented free vibration of curved panels using ANSYS with eight-noded isoparametric layered shell elements. A comparison was made between curved isotropic and orthotropic panels with a view to reducing the weight of curved isotropic panels. The modal characteristics of curved panels with cantilever boundary condition are isotropic (aluminium) and orthotropic (carbon-epoxy composite). The fibre angle changes and stacking sequences result in various dynamic components behaviour, i.e. various natural frequencies for the same geometry, mass and boundary conditions. They highlighted the selection of the angle of fibre orientation can change the natural frequencies to control the level of vibration. Mitao Ohga et al. [106] used the transfer matrix approach to obtain natural frequencies and vibration mode modes of curved panels with variable thicknesses. The transfer matrix is derived by using Fourier-series expansions in the longitudinal direction and then a numerical integration in the circumferences of the curved panels. The effects of the thickness ratio of the cross section on the natural frequencies and mode shapes were examined. Minh Tu Tran et al. [40] carried out an analytical solution for vibration analysis of stiffened cross-ply laminated composite doubly curved shallow shell panels resting on the elastic foundation with the simply supported boundary condition by using first-order shear deformation theory. It investigates the impact of the number of stiffeners, the heightto-width ratio of stiffeners, and the number of layers of laminated composite shells on stiffened shell deflections with and without elastic foundation. The findings of this analysis show that the fundamental frequency of shell panel with orthogonal stiffeners (both cylindrical shell panel and spherical shell panel) is the smallest (stiffest) if the height-to-width ratio of the stiffener decreases. The elastic foundations increase the fundamental natural frequency of the stiffened, doubly curved shallow, cross-laminated composite shell. Biswal et al. [70] carried out free vibration analyses of higher-order shear deformable doubly curved laminated shell panels and a general formulation is presented developed in the MATLAB. The proposed theory about shear deformation ensures that transverse shear strains are changed parabolically through the thickness of the shell and that body movement is rigid. The effects on the natural frequencies of shell panels of different parameters like the thickness ratio, curvature, orthotropic ratio, lamination scheme, number of piles, boundary conditions and shell geometries are examined. The fundamental frequencies are found to increase with an increase in thickness ratio, ratio of principal radii of curvatures, and orthotropic ratio, but exhibit a decreasing trend with an increase in aspect ratio and radii of curvatures. Pradyumna et al. [71] performed free vibration analyses for cylindrical (CYL), spherical (SPH), hyperbolic paraboloid (HPR), hypar (HYP), and conoid (CON) shell panels made of FGMs. The characteristics of FGM are regarded as temperature-dependent and are graded to a thickness level by simple distribution of power-law components in terms of volume fractions. The effects on the free vibration of geometric characteristics, material composition, and boundary conditions are investigated. Results show that natural frequencies increase as the curvature parameter is increased. The CL boundary condition shell panels provide the highest natural frequency values, followed by SS and CS boundary conditions of shell panels in all five shell panels. Achchhe Lal et al. [107] presents free vibration response from the geometrically conical piezo laminated shell panel subjected to nonlinear finite-element thermo-electric charge. Parameter studies investigate the effect of amplitude ratios, stacking sequences, cone angles, piezoelectric layers, applied voltages, circumference length to thickness, temperature variations and boundary support conditions. From the analysis it can be concluded that the nonlinear natural frequency of conical shell panel increases with increase in length to curvature ratios, increase the amplitude ratio and frequency mode, increases with piezoelectric layers. All edges clamped supported conical shell panel shows higher nonlinear natural frequency as compared to simply supported and clamped and simply supported. Kar et al. [108] investigated the free vibration responses of simply-supported FG flat/curved shell panels are examined under elevated thermal environments. The responses are numerically calculated using a generalized mathematical model developed in conjunction with the finite element method under three different temperature loading conditions (uniform, linear and nonlinear) within the framework of HSDT mid-plane kinematics. The 
effects of different geometric and material parametres are discussed on the frequency response of single/doubly curved and flat panels. The following conclusions are based on the present parametric analysis of the FG flat/curved shell panels: It is observed that the frequency response increases as the thickness ratio increases and the aspect ratio increases irrespective of the geometries of the FG shell panel. When the power-law indices and the curvature ratios increase, the frequency responses decrease. The frequency parameter for each shell geometry is decreasing with the increase of temperature load. Vu Van Tham et al. [109] carried out free vibration analysis based on the new four variable theory of the refined shell for functionally graded carbon nanotube enhanced composite (FG-CNTRC) panels. Studied different parameters such as the FG-CNTRC, curvature, thickness ratio, aspect ratio and the number of layers on free vibration reaction of panels. The numerical results showed the accuracy and performance of the constructed model in the comparison with literature examples. The findings showed that the shell panels get stiffer with increasing curvature, while the panel rigidity decreases with increasing aspect ratio.

\subsection{Free Vibration Analysis of cylindrical shell}

Singh et al. [110] carried out free vibration analysis of laminated composite cylindrical panels on a rectangular base using an 8-noded isoparametric element of ANSYS. For various boundary conditions, the effects of several parameters such as radius-to-side ratios, side to thickness ratio and various laminations are discussed. With the increase in the curvature ratio $(\mathrm{R} / \mathrm{a})$ and thickness ratio $(\mathrm{a} / \mathrm{h})$ the non-dimensional basic natural frequency of the simply supported cross-ply cylindrical shells decreases. Chougale et al. [111] have done experimental and numerical analysis using the finite element method for understanding the mechanical behaviour of the cantilever rod made of carbon fibre composite material. Natural frequencies of both steel and composite material are calculated using FFT analysis and results are validated by modal analysis in ANSYS. It is observed that natural frequencies are much higher for laminated carbon composite than steel. It is suggested that the use of laminated carbon composite is useful instead of steel in various applications to maintain high frequencies. P. Dongare et al. [43] analyzed modal analysis of a composite drive shaft for power transmission applications using FEM. Composite shaft analysis is conducted to find the effect on the carriage capacity of the drive shaft of the fibre orientation. It is shown that 2nd, 3rd, 4th and 5 th natural frequencies increase with angle of orientation and then remains constant.

\section{Conclusions}

Based on the above study of laminated composite flat panel, curved panel and cylindrical shells conclusions are summerrized. Composite materials are becoming increasingly important in the development of aerospace structures and have attractive aspects, such as relatively high compressive strength, good adaptability in the manufacture of thick composite shells, low weight, low density and resistance to corrosion. Stacking pattern is an important characteristic of the composite plate design. The guidelines for symmetry and balance aim to avoid coupled behaviors of shear-extension and membrane-bending, respectively. The value of maximum stress \& strain increases with the type of circular, square, triangular and hexagonal cutout. For all plates the variation of stress concentration factor (SCF) is more in orthotropic plate compared to isotropic plate. The deflections of the shell panels with orthogonal stiffeners (both the cylindrical shell panel and the spherical shell panel) are the smallest for static analyses when the ratio of height to width increases.The stability resistance of plate increases with increase of number of layers due to effect of bending-stretching coupling. The buckling loads reduce significantly depending upon the side-tothickness ratios and aspect ratios. Composite laminated plate with rectangular and square cutout shows a decrease in buckling load carrying capacity compared to circular cutout plates. It is observed that the critical buckling load of CCCC boundary condition is higher than the other and is less for SSSS boundary condition. The non-dimensionalized buckling load increases for symmetric laminates, while it decreases under uniaxial and biaxial compressive loads for antisymmetric laminates as the modulus ratio increases. The different fiber orientation angle affects the critical buckling load. It is noted that cutout presence reduces the buckling load. It has been observed that buckling loads increased with an increase in the number of layers of carbon 
fibre in CFRP plates. The non-dimensional fundamental vibration frequency is observed to, increase with an increase in fibre orientation angle and number of layers for all the support conditions due to bending stretching coupling, but decrease with an increase in aspect ratio and thickness to width ratio. The frequency of vibration was noted to be highest for fully clamped condition due to the increased stiffness. Natural frequencies for the cross-ply is higher than the angle ply, symmetric ply is higher than the antisymmetric ply and CFRP composite plates higher than for GFRP composites. Increasing number of plies causing the basic natural frequency of unsymmetric cross-ply laminate to rise.

\section{Competing Interests}

We declare that we have no significant competing financial, professional, or personal interests that might have influenced the performance or presentation of the work described in this manuscript.

\section{How to Cite this Article:}

Sreadha A R and C. Pany, "Static, Free Vibration and Buckling Analysis of Composite Panels; A Review", Adv. J. Grad. Res., vol. 9, no. 1, pp. 21-45, Nov. 2020. https://doi.org/10.21467/ajgr.9.1.21-45

\section{References}

[1] Autar K. Kaw , Mechanics of composite materials ,2nd ed , vol 29, 2006 by Taylor \& Francis Group, LLC

[2] Robert M Jones, Mechanics of composite materials, Second edition by Taylor \& Francis Group, LLC

[3] ASTM D 3039/D 3039 N, Standard test method for tensile properties of polymer matrix composite materials.

[4] Nikhil V Nayak "Composite Materials in Aerospace Applications" International Journal of Scientific and Research Publications, vol 4, no 9, Sep2014. pp. $1-10$.

[5] Maria mrazova “Advanced composite materials of the future in aerospace industry" INCAS BULLETIN, vol 5, no 3, 2013, pp. 139 - 150. DOI: 10.13111/2066-8201.2013.5.3.14

[6] Gourav Gupta et al. "Application and Future of Composite Materials: A Review" International Journal of Innovative Research in Science, Engineering and Technology, vol 5, no 5, May 2016, pp.6907 - 6911. DOI:10.15680/IJIRSET.2016.0505041

[7] https://www.astm.org/Standards/D8066.htm

[8] Prashanth Turla et al. "Interlaminar Shear Strength of Carbon Fiber and Glass Fiber Reinforced Epoxy Matrix Hybrid Composite",IJREAT, vol 2, no 2, pp:1-4, Apr-May, 2014.

[9] Züleyha Aslan et al. "Characterization of interlaminar shear strength of laminated woven E-glass/epoxy composites by four point bend shear test", Polymercomposite, vol 31, no 2, Feb 2010, pp: 359-368. DOI: https://doi.org/10.1002/pc.20819

[10] Haftka R.T et al. "Optimum Design of Laminated Composite Structures”, In: Elements of Structural Optimization. Solid Mechanics and Its Applications, Springer, Dordrecht, vol 1, 1990, pp: 341-384.

[11] F.X. Irisarria et al. "Optimal design of laminated composite structures with ply drops usingstacking sequence tables", Composite Structures,vol 107, January 2014, pp:559-569. DOI: 10.1016/j.compstruct.2013.08.030

[12] MIL-HDBK-17-3F, “Composite Materials Handbook - Polymer Matrix Composites, Materials Usage, Design, and Analysis”, vol 3, June 2002.

[13] J.A.Bailie et al. “ A summary and review of composite laminate design guidelines” (Technical report NASA No. NAS1-19347), Jun 1997-Oct 1997,pp:1-76.

[14] Alexis Lasseigne, "Optimization of variable-thickness composite structures. Application to a CROR blade", Materials. UNIVERSITE DE LYON, Jan 2016.

[15] http://www.ist.edu.pk/downloads/amss/lecturers/design-guidelines.pdf

[16] Abdalla MM et al. "Formulation of composite laminate robustness constraint in lamination parameters space". In: Proceedings of 50th AIAA/ASME/ASCE/AHS/ASC structures, structural dynamics, and materials conference. Palm Springs, California; Jun 2012,pp:1-15.DOI: https://doi.org/10.2514/6.2009-2478

[17] https://www.performancecomposites.com/about-composites-technical-info/124-designing-with-carbon-fiber.html

[18] Rakesh Vishwakarma et al. "Stress analysis of laminated composite plate using F. E. M" International Journal of Application or Innovation in Engineering \& Management, vol 4, no 1, 2015,pp. 107 - 125.

[19] Yenda kesavarao et al."Stress analysis of laminated graphite/epoxy composite plate using fem" International Journal of Mechanical Engineering, vol 4, no 5, Aug-Sep 2015, pp. 9 - 16.

[20] N. Moubayeda et al. "Static Analysis of an Orthotropic Plate" J.Material Science @ Elsevier Ltd, Physics Procedia 55, 2014 , pp. 367 - 372. DOI: 10.1016/j.phpro.2014.07.053

[21] Niral R.Patel et al. "A Research Paper on Static Analysis of Laminated Composite Plate” Indian Journal Of Research, vol 3 , no 5, Jun 2013,pp:82-84.

[22] Junaid Kameran Ahmed et al. "Static and Dynamic Analysis of Composite Laminated Plate " International Journal of Innovative Technology and Exploring Engineering, vol 3,no 6,Nov 2013, pp: 56-60. DOI : 10.1.1.674.6951

[23] J. S. Kalyana Rama et al. "Finite Element modeling of an orthotropic laminated plate under cylindrical bending"IOSR Journal of Mechanical and Civil Engineering, vol 3, no 5, Sep-Oct 2012, pp. 35 - 41. DOI: 10.9790/1684-0353541

[24] R. R. Singh et al. "Analysis of stiffened isotropic and composite plate” International Research Journal of Engineering and Technology, vol 03, no 02, Feb 2016, pp. $1-7$. 
[25] Rahul Patwa et al. "Analysis of Cross-ply Laminate composite under UD load based on CLPT by Ansys APDL" Int.Journal of Engineering Research and Applications,vol 5, no 9,Sep 2015 , pp:90-94.

[26] Woraphon Niamnin et al. "Numerical Investigation on Symmetrical Bending of Uniformly Strip Loaded Square Plates with Different Support Conditions" Advanced Studies in Theoretical Physics, vol 9, no 9 , 2015 , pp. 395 - 410. DOI: http://dx.doi.org/10.12988/astp.2015.5452.

[27] G. C. Mekalke et al. "Analysis Of A Plate With A Circular Hole By Fem" IOSR Journal of Mechanical and Civil Engineering, ISSN:2278-1684, 2013, pp:25-30.

[28] Dr. Riyah N.K.et al. "Stress Analysis of Composite Plates with Different Types of Cutouts" Anbar Journal of Engineering Sciences, vol 2, no 1, 2009, pp: $11-29$.

[29] Victor Debnath et al. "Deflection And Stress Analysis Of A Beam On Different Elements Using Ansys Apdl" International Journal of Mechanical Engineering and Technology, vol 5, no 6, Jun 2014 pp: 70-79.

[30] Vanam B. C. L et al. "Static analysis of an isotropic rectangular plate using finite element analysis (FEA)" Journal of Mechanical Engineering Research, vol 4, no 4 , Apr 2012, pp: 148-16. DOI: 10.5897/JMER11.088

[31] M. L. Pavan Kishore et al. "Stress analysis of rectangular and square plates with various cutouts" ISSN, vol 22, Oct 2018, pp: 165169. DOI https://doi.org/10.21595/vp.2018.20311

[32] Sridhara Raju. V.V etal."Effect of Thickness Ratio on Nonlinear Static behaviour of Skew Bidirectional FRP Laminates with Circul ar Cutout”International Journal Of Applied Engineering Research, vol 1, no 4, 2011, pp: 923-932.

[33] Dr.Abdul siddique shaik et al. "Stress Concentration of Rectangular Plate with a Hole Made With Composite Material Using Finite Element Analysis" IOSR Journal of Mechanical and Civil Engineering (IOSR-JMCE), vol 13, no 4, Jul. - Aug 2016, pp: 1-5. DOI: 10.9790/1684-13040740105

[34] Nitin Kumar Jain "Analysis of Stress Concentration and Deflection in Isotropic and Orthotropic Rectangular Plates with Central Circular Hole under Transverse Static Loading" International Journal of Mechanical, Aerospace, Industrial, Mechatronic and Manufacturing Engineering, vol 3, no 12, 2009, pp: 1513-1519.

[35] K. Kalita et al. "Static Analysis of Transversely Loaded Isotropic and Orthotropic Plates with Central Cutout", J. Inst. Eng. India Ser. C, vol 95. no 4, October-December 2014, pp:347-358 . DOI 10.1007/s40032-014-0138-9

[36] Ramindla Praveenet al. "Design, Static Structural and Modal Analysis of Aircraft Wing (Naca 4412) Using Anasys Workbench 14.5" International Journal of Engineering Science Invention, vol 7, no 12, Dec 2018, pp: 61 - 71.

[37] Gururaj.M.Kumbar et al. "Static And Buckling Analysis of Fuselage Panel under Varied Flight Condition's" International Journal of Engineering Research in Mechanical and Civil Engineering (IJERMCE), vol 2, no 11, 2017, pp:121 - 127.

[38] V. J. K. Silpa et al."Structural Analysis of Thin Isotropic and Orthotropic Plates using Finite Element Analysis" SSRG International Journal of Mechanical Engineering (SSRG - IJME), vol 4, no 6, 2017, pp:13 - 24. DOI:10.14445/23488360/IJME-V4I6P104

[39] Trung Thanh Tran et al. "Static and free vibration analyses of functionally graded porous variable-thickness plates using an edgebased smoothed finite element method.” Defence Technology, Jun 2020, DOI: https://doi.org/10.1016/j.dt.2020.06.001.

[40] Minh Tu Tran et al."Static and vibration analysis of cross-ply laminated composite doubly curved shallow shell panels with stiffeners resting on Winkler-Pasternak elastic foundations" Int J Adv Struct Eng ,vol 9, May 2017, pp :153 - 164. DOI : https://doi.org/10.1007/s40091-017-0155-z

[41] Anusha Gampala et al. "Linear Static Analysis of a Curved Shell with Circular Cutout Subjected to Tensile Load Using Finite Element Approach”, International Journal of Engineering Research \& Technology, Vol 03 , No 08, Aug 2014, pp:839-843

[42] M. Cinefra et al. "A variable kinematic doubly-curved MITC9 shell element for the analysis of laminated composites", Mechanics of Advanced Materials and Structures, Oct 2015 , DOI: 10.1080/15376494.2015.1070304

[43] Miss. Priya Dongare et al. "Effect of Fiber Angle Orientation on Stress, Deformation and Buckling Torque of the Composite Drive Shaft" Global Journal of Researches in Engineering Mechanical and Mechanics Engineering, vol 13 , no 6, Jan 2013, pp: 1-8.

[44] K. Chandrashekhara et al. "Static analysis of a thick laminated circular cylindrical shell subjected to axisymmetric load" Composite Structures Elsevier Science Publishers Ltd,vol 23, 1993 pp:1-9. DOI: https://doi.org/10.1016/0263-8223(93)90068-2

[45] S. Mahmoud Mousavi et al. "Static Bending Analysis Of Laminated Cylindrical Panels With Various Boundary Conditions Using The Differential Cubature Method”, Journal Of Mechanics Of Materials And Structures, Vol. 4, No. 3, Mar 2009,pp:509-521

[46] Leissa A. W. Buckling of Composite Plates, Composite Structures, vol 1,1983, pp: 51-66. DOI: https://doi.org/10.1016/02638223(83)90016-8

[47] Dr. P. Ravinder Reddy et al. "Buckling Analysis of Orthotropic Laminated Composite Plate With Rectangular Cut-Outs By Using FEA" International Journal of Emerging Technologies in Computational and Applied Sciences, vol 14, no 717, 2014, pp:75 - 81 . DOI: 10.1016/j.advengsoft.2009.09.005.

[48] Anu George et al. "Optimization of Different Shape of Cutouts by Buckling Analysis of Laminated Composite Plate" IOSR Journal of Mechanical and Civil Engineering, 2016, pp:21 - 25.

[49] K.Mallikarjuna Reddy et al. Buckling Anlysis of Laminated Composite Plates Using Finite Element Method "International Journal Of Engineering Sciences \& Research Technology", vol 2, no 11, Nov 2013, pp:3281 - 3286.

[50] Prabhakaran.V et al."Finite Element Analysis of Composite Structures Under Different Types of Loads" International Journal of Engineering Science and Computing, vol 6, no 8, Aug2016, pp:2631-2635.

[51] Nagendra Singh Gaira et al. "Linear buckling analysis of laminated composite plate"International journal of engineering science \& advanced technology, vol 2, no 4 , Jul-Aug 2012, pp: 886 - 891.

[52] A.Joshi Gowri Sankar eta al. " Buckling Analysis of Thin Carbon/Epoxy Plate by Using FEA" International Journal of Engineering Research \& Technology, vol 2 , no 9, Sep 2013, pp:515 - 523

[53] Ahmed Hassan Ahmed Hassan et al. "Modeling and Buckling Analysis of Rectangular Plates in ANSYS" International Journal of Engineering \& Applied Sciences, vol 11, no 1, 2019, pp:310 - 329. DOI: https://doi.org/10.24107/ijeas.531011.

[54] R J Fernandes etal."Buckling Analysis of Laminated Composite Plate Using Finite Element Software" International Journal of Civil Engineering Research, vol 9, no 1,2018, pp:11-19. 
[55] S. Prashanth et al. "Nonlinear Buckling Analysis of Laminated Composite Twisted Plate" Research Journal of Engineering Sciences, vol 4, no 4, Apr 2015, pp:1-8.

[56] Dilu Riswana C et al."Buckling Analysis Of Laminar Composite Plates With Cutouts"International Research Journal of Engineering and Technology, vol 3, no 8, Aug2016, pp: 1985-1989.

[57] Pavol Lengvarský et al. "The Buckling Analysis of the Composite Plates with Different Orientations of Layers" American Journal of Mechanical Engineering, vol 4, no 7, 2016, pp: 413-417. DOI:10.12691/ajme-4-7-33

[58] Mr. Madhu Kumar M et al. "Linear Buckling Analysis of S-Glass/Epoxy Laminated Composite"International Journal for Scientific Research \& Development, vol 4, no 8, Nov 2016, pp:184-189.

[59] A Lakshmi Narayan et al."Buckling analysis of rectangular composite plates with rectangular cutout subjected to linearly varying inplane loading using fem" Indian Academy of Sciences, vol 39 , no 3,Jun 2014, pp:583-596. DOI: 10.1007/s12046-014-0250-9

[60] Mohammad Amin Torabizadeh "Buckling of the composite laminates under mechanical loads with different layups using different plate theories" Advanced Composites Letters, vol 24, no 1,Jan 2015, pp:12-20. DOI: 10.1177/096369351502400103

[61] M. Aydin Komur et al. "Buckling analysis of laminated composite plates with an elliptical/circular cutout using FEM"J.advengsoft. Elsevier Ltd, vol 41, pp:161-164. DOI :10.1016/j.advengsoft.2009.09.005

[62] Ravi Kumar Pa et al. " Linear Buckling Analysis and Comparative Study of Unstiffened and Stiffened Composite Plate" J.Material Science () Elsevier Ltd,vol 5 ,2018, pp: 6059-6071. DOI: https://doi.org/10.1016/j.matpr.2017.12.211.

[63] Z. Y. Han et al. "Buckling analysis of laminated composite plates with variable fibre orientation angle" Materials Research Innovations $\odot$ W. S. Maney \& Son Ltd, vol 19, no 5 , Dec 2014, pp:836 - 842. DOI 10.1179/1432891714Z.0000000001204

[64] Buket okutan baba"Buckling Behavior of Laminated Composite Plates" Journal of reinforced plastics and composites, vol 26, no 16, Sep 2007, pp: 1637-1655. DOI: 10.1177/0731684407079515

[65] Murat yazici "Influence of Cut-Out Variables on Buckling Behavior of Composite Plates" Journal of reinforced plastics and composites, vol 28, no 19, Sep 2009, pp:2325 - 2339. DOI: 10.1177/0731684408092058

[66] Dhiraj Patil et al. "Vibration and Buckling Analysis of Composite Plate" International Engineering Research Journal, vol 2, no 7, Jan 2017, pp: 2376-2379.

[67] J. N. Reddy et al. " Buckling and vibration of laminated composite plates using various plate theories", AIAA Journal, Vol 27,No 12, Oct 2013, pp: 1808-1817, DOI: https://doi.org/10.2514/3.10338

[68] Anish et al. "Bi-Axial Buckling of Laminated Composite Plates Including Cutout and Additional Mass", Materials, Vol 12, No 1750, May 2019, pp: 1-23, DOI:10.3390/ma12111750.

[69] Mark W. Hilburger et al. "Nonlinear and buckling behavior of curved panels subjected to combined loads" American Institute of Aeronautics and Astronautics,2001, pp:1 - 12.

[70] D. K. Biswal et al. " Free vibration and buckling study of doubly curved laminated shell panels using higher order shear deformation theory based on Sander's approximation", Proceedings of the Institution of Mechanical Engineers, Part C: Journal of Mechanical Engineering Science, Vol 232, Issue 20, Oct 2017. pp: 1-17, DOI: https://doi.org/10.1177/0954406217740165.

[71] S. Pradyumna et al. " Free Vibration And Buckling Of Functionally Graded Shell Panels In Thermal Environments", International Journal of Structural Stability and Dynamics, Vol 10, No 05, 2010 , pp. 1031-1053 , DOI: 10.1142/S0219455410003889

[72] T Subramani et al. "Finite Element Analysis of Thin Walled-Shell Structures by ANSYS" International Journal of Modern Engineering Research,vol 2 , no 4, Aug 2012, pp:1576-1587.

[73] Leissa. A.W, “A Review of Laminated Composite Plate Buckling”. Appl. Mech. Rev, vol 40,no 5, May 1987, pp: 575-591. DOI: https://doi.org/10.1115/1.3149534

[74] Kapania. R.K et al. "Recent Advances in Analysis of Laminated Beams and Plates, Part ii: Vibrations and Wave Propagation" AIAA Journal, vol 27, no 7, July 1989 , pp: 935-946. DOI: https://doi.org/10.2514/3.59909

[75] HamidrezaAllahbakhsh et al. "Buckling Analysis of Laminated Composite Panel with Elliptical Cutout Subject to Axial Compression" Hindawi Publishing Corporation Modelling and Simulation in Engineering, Nov 2012, pp: 1-10. DOI: https://doi.org/10.1155/2012/171953

[76] Liew. K.M et al. " Research on thick plate vibration: A literature survey”. Journal of sound and vibration, vol 180, no 1,Feb 1995, pp:163-176. DOI : https://doi.org/10.1006/jsvi.1995.0072.

[77] Zhang. Y.X et al. "Recent developments in finite element analysis for laminated composite plates", Composite Structures, vol 88, 2009, pp: 147-157. DOI :10.1016/j.compstruct.2008.02.014

[78] Ajay Dnyaneshwar Landge et al. "Free and forced vibration of a laminate structure with different material configuration \& angle orientation by using finite element analysis" International Journal for Research in Applied Science \& Engineering Technology, vol 5, no IX, Sep 2017, pp:1800-1810. DOI: 10.22214/ijraset.2017.9261

[79] Devidas R. Patil et al. "Vibration Analysis of Composite Plate at Different Boundary Conditions" International Journal of Innovative Research in Science, Engineering and Technology, vol 3, no 12, Dec 2014, pp: 18089 - 18094 . DOI: 10.15680/IJIRSET.2014.0312046.

[80] C Naveen Raj et al. "Dynamic Analysis of Composite Plate using Finite Element Analysis" International Journal of Engineering Research \& Technology, vol 5, no 11, Nov 2016, pp: 270-280.

[81] Pushpendra k. kushwaha et al. "Study of Vibration Analysis of Laminated Composite Plates Using FEM" International Journal of Advanced Mechanical Engineering, vol 4, no 6, 2014, pp: 675-680.

[82] Aishwary Singh Rajawat et al. "Free vibration analysis of Stiffened Laminated Plate using FEM" J.Material Science (C) Elsevier Ltd, vol 5, no 2, Jan 2018, pp: 5313-5321. DOI: 10.1016/j.matpr.2017.12.115.

[83] M.T.Ahmadian et al."Forced Vibration Analysis Of Laminated Rectangular Plates Using Super Elements" J.Scientia Iranica, vol 10, no 2, Apr 2003 pp: 260 - 265.

[84] Satyendra Singh Gurjar et al. "Vibration Analysis of moderately thick symmetric cross laminated composite Plate using FEM" IJSRSET, vol 3, no 3, May-June 2017, pp: 500 - 510.

[85] Pushparaj Pingulkar et al. "Free Vibration Analysis of Laminated composite Plates using Finite Element Method"J. Polymers \& Polymer Composites, vol 24, no 7, Sep 2016, pp:529 - 538. DOI : https://doi.org/10.1177/096739111602400712 
[86] Dr. Ibtehal Abbas Sadiq etal."Non-Linear Free Vibration Analysis Of Composite Laminated Plates" The Iraqi Journal For Mechanical And Material Engineering, vol 17, no 2 , July 2017, pp: 337-353.

[87] Mohammed Salih Hassan AL-Araji et al. "Free Vibration Analysis of Perforated Laminated Composite Square Plates" Journal of University of Babylon for Engineering Sciences, vol 26, no 10, 2018, pp:335 - 345.

[88] N Mishra et al."Free vibration Analysis of Sandwich Plates with cutout” IOP Conf. Series: Materials Science and Engineering, vol 149, Sep 2016,pp:1 - 6. DOI: 10.1088/1757-899X/149/1/012149

[89] M. K. Pandit et al. "Free Vibration Analysis of Laminated Composite Rectangular Plate Using Finite Element Method" Journal of Reinforced Plastics and Composites, vol 26, no 1, 2007, pp: 69 - 80. DOI: 10.1177/0731684407069955

[90] Manoj Narwariya etal. "Harmonic analysis of moderately thick symmetric cross-ply laminated composite plate using FEM" ISSN Advances in Computational Design, vol 3, no 2, Apr 2018, pp: 113 - 132. DOI: 10.12989/acd.2018.3.2.113

[91] Prachi Sia et al. "Free Vibration Analysis Of Laminated Composite Beams" Indian J.Sci.Res, vol 14, no 2, 2017, pp: $270-275$.

[92] Sumit Khare et al."Three-dimensional free vibration analysis of thick laminated circular plates" International Journal of Engineering, Science and Technology, vol 8, no 2, 2016, pp:11 - 29.

[93] M. Ganapathi et al. "Free vibration analysis of simply supported composite laminated panels" J.compstruct Elsevier Ltd, Volume 90, Sep 2009, pp: 100-103. DOI: https://doi.org/10.1016/j.compstruct.2009.02.003

[94] Arafa El-Helloty "Free Vibration Analysis of Stiffened Laminated Composite Plates" International Journal of Computer Applications ,vol 156, no 1, Dec 2016, pp:12-23.

[95] Sharayu U. Ratnaparkhi et al. "Vibration Analysis of composite plate" International Journal of Modern Engineering Research, vol 3, no 1, Jan-Feb 2013, pp:377 -380. DOI=10.1.1.436.8370

[96] Itishree Mishra, “Parametric Instability of Woven Fiber Composite Plates”, MTech Thesis, NIT Rourkela,July 2012.

[97] Chai, G.B et al. "Vibration analysis of laminated composite plates: TV-holography and finite element method", Composite Structures, vol 23, no 4 ,1993, pp: 273-283. DOI : 10.1016/0263-8223(93)90228-I

[98] Chakraborty. S.et al “ Free vibrational responses of FRP composite plates: experimental and numerical studies”, Journal of Reinforced Plastics and Composite, vol 19, no 7 Jan 2000, pp: 535-551. DOI: 10.1106/FU67-2AVN-H1N5-N1GV

[99] Shun-Fa Hwang et al. "Determination of elastic constants of materials by vibration testing", Composite Structures, vol 49, no 2 Jun 2000, pp: 183-190. DOI: 10.1016/S0263-8223(99)00132-4.

[100] Lei X et al. "Vibration characteristics of glass fibre- epoxy composites with different woven structure", Journal of Composite Materials, vol 45, no 10, 2010,pp: 1069-1076. DOI: 10.1177/0021998310377943

[101] M. Nasihatgozar et al. "Free Vibration of a Thick Sandwich Plate Using Higher Order Shear Deformation Theory and DQM for Different Boundary Conditions", Journal of Applied and Computational Mechanics, Vol 3, No 1, Jan 2017, pp: 16-24, DOI: 10.22055/jacm.2017.12548.

[102] C.K. Hirwani et al. "Nonlinear Free Vibration Analysis of Laminated Carbon/Epoxy Curved Panels" Defence Science Journal, vol 67, no 2, Mar 2017, pp: 207 - 218. DOI : 10.14429/dsj.67.10072.

[103] SarmilaSahoo "Free vibration behavior of laminated composite stiffened elliptic parabolic shell panel with cutout" De Gruyter Reasearch Article. CurvedandLayer.Struct, vol 2, Mar 2015, pp:162 - 182. DOI: https://doi.org/10.1515/cls-2015-0009

[104] Charu Lakshmi .S et al. “Free Vibration Analysis of Laminated Composite Cylindrical Panel Using ANSYS” International Journal of Innovative Research in Science, Engineering and Technology ,vol 4, no 12, Sep 2015, pp: 53 - 57.

[105] K. Karthik et al. "Free Vibration Characteristics Analysis of Prediction Modal Orthotropic Curved Panel by Using Finite Element Method" Journal of Chemical and Pharmaceutical Sciences, no 7, May 2017, pp:71 - 76.

[106] Achchhe Lal et al. " Thermoelectrically induced nonlinear free vibration analysis of piezo laminated composite conical shell panel with random fiber orientation.”, Curved and Layer. Struct. Vol 4 , Nov 2017; pp :237-254.

[107] V.R. Kar et al. "Free vibration responses of temperature dependent functionally graded curved panels under thermal environment." Latin American Journal of Solids and Structures , Vol 12, July 2015, pp: 2006-2024, DOI:http://dx.doi.org/10.1590/167978251691

[108] Vu Van Tham et al. "Free Vibration Analysis of Laminated Functionally Graded Carbon Nanotube-Reinforced Composite Doubly Curved Shallow Shell Panels Using a New Four-Variable Refined Theory”, J. Compos. Sci ,Vol 3, No 104, Dec 2019, pp: 1-22, DOI:10.3390/jcs3040104.

[109] Mitao Ohga et al. "Vibration analysis of curved panels with variable thickness" Engineering Computations, vol 13, no 2, Mar 1996, pp : 226-239. DOI: 10.1108/02644409610114549

[110] Vijay K. Singh et al. "Free Vibration Analysis of Laminated Composite Cylindrical Panels" International Journal of Engineering Science Invention, 2017, pp:85-88.

[111] S.V.Chougale et al. "Comparative Study of Carbon Fiber Composite rod with Steel by using Modal Analysis and FEA" International Journal of Innovative Research in Science, Engineering and Technology, vol 6, no 11,Nov 2017, pp: 21671-21678. DOI:10.15680/IJIRSET.2017.0611100

Publish your books with AIJR publisher-

* Publish with ISBN and DOI.

* Publish Thesis/Dissertation as Monograph.

* Publish Book Monograph.

- Publish Edited Volume/ Book.

* Publish Conference Proceedings

* Retain full copyright of your books.

Submit your manuscript at books.aijr.org
Publish your research article in AIJR journals-

* Online Submission and Tracking

* Peer-Reviewed

* Rapid decision

* Immediate Publication after acceptance

* Articles freely available online

* Retain full copyright of your article. Submit your article at journals.aijr.in 